\title{
The Commitment Role of Equity Financing
}

\author{
by
}

Matthias FAHN

Valeria MERLO

Georg WAMSER

Working Paper No. 1712

July 2017

Johannes Kepler University of Linz Department of Economics Altenberger Strasse 69 A-4040 Linz - Auhof, Austria www.econ.jku.at 


\title{
The Commitment Role of Equity Financing*
}

\author{
Matthias Fahn† Valeria Merlo
}

July 7,2017

\begin{abstract}
Existing theories of a firm's optimal capital structure seem to fail in explaining why many healthy and profitable firms rely heavily on equity financing, even though benefits associated with debt (like tax shields) appear to be high and the bankruptcy risk low. This holds in particular for firms that show a strong commitment towards their workforce and are popular among employees. We demonstrate that such financing behavior may be driven by implicit arrangements made between a firm and its managers/employees. Equity financing generally strengthens a firm's credibility to honor implicit promises. Debt, however, has an adverse effect on the enforceability of these arrangements because too much debt increases the firm's reneging temptation, as some of the negative consequences of breaking implicit promises can be shifted to creditors. Our analysis provides an explanation for why some firms only use little debt financing. Predictions made by our theory are in line with a number of empirical results, which seem to stay in contrast to existing theories on capital structure.
\end{abstract}

JEL Codes: C73, D24, D86, G32

Keywords: relational contracts, capital structure, corporate finance, debt financing

${ }^{*}$ We thank Ricardo Alonso, Daniel Barron, Felipe Balmaceda, Mike Fishman, Florian Englmaier, Nicola Gennaioli, Ricard Gil, Hendrik Hakenes, Daniel Herbold, Jin Li, Niko Matouschek, Mike Powell, Jean-Charles Rochet, Klaus Schmidt, Monika Schnitzer, Caspar Siegert, Marta Troya Martinez and Robert Ulbricht, as well as seminar participants at the LMU Munich, the 1st Bavarian Micro Workshop (Regensburg), the 16th Colloquium on Personnel Economics (Tuebingen), the 11th IIOC (Boston), the 2013 EEA meeting (Gothenburg), and the 2013 EARIE meeting (Evora) for helpful comments. Matthias Fahn gratefully acknowledges financial support from the German Science Foundation (DFG) through collaborative research center CRC TRR 190.

${ }^{\dagger}$ Affiliation: University of Munich and CESifo. Address: LMU Munich, Chair of Organizational Economics, Kaulbachstr. 45, 80539 Muenchen, Germany. E-mail: matthias.fahn@econ.lmu.de.

${ }^{\ddagger}$ Affiliation: University of Tuebingen and CESifo. Address: University of Tuebingen, Mohlstrasse 36, 72074 Tuebingen, Germany. E-mail: E-mail: valeria.merlo@uni-tuebingen.de.

$\S$ Affiliation: University of Tuebingen, CESifo and NoCeT. Address: University of Tuebingen, Mohlstrasse 36, 72074 Tuebingen, Germany. E-mail: georg.wamser@uni-tuebingen.de. 


\section{Introduction}

Many firms seem substantially underleveraged, given existing theories on a firm's optimal financing structure. These theories usually assume that higher debt increases the risk of bankruptcy, which imposes substantial costs on creditors, suppliers or employees. Yet many profitable and healthy firms - with negligible bankruptcy risk - have very little (or even no) debt, suggesting that substantial tax shields are left on the table. ${ }^{1}$

Leverage appears to be particularly low at firms with a strong commitment for treating their employees well and keeping promises made to their workforce. A prominent example is Lincoln Electric, a leading manufacturer of welding products (and subject of one of the most successful Harvard Business School case studies). Lincoln Electric has motivated its employees since 1934 with the promise to share a significant amount of profits with them. In addition, the firm has hardly used any debt throughout most of its history, which, according to former CEO Donald F. Hastings, was a fundamental component of its whole implicit incentive system. This became apparent when Lincoln Electric substantially increased leverage in the mid-nineties after an unsuccessful international expansion, making employees worried whether the firm would still keep its promises in the future (Hastings, 1999, p. 166). Another example is Southwest Airlines. This company is well-known for being an employer with a strong commitment towards its workforce ${ }^{2}$ and, compared to its domestic competitors, Southwest also has a much lower debt ratio. ${ }^{3}$

In this paper, we show how equity financing can foster employees' beliefs that a firm will honor implicit promises. The commitment to honor these promises is modelled as credibility in relational contracts formed with a manager or with employees. Debt has a negative impact on the enforceability of relational contracts because the consequences of reneging on implicit promises made to employees are partially shifted to creditors. Upon reneging, expected (re-)payments made to creditors are reduced since the firm is less profitable and hence faces a higher bankruptcy risk. Therefore, debt increases the firm's reneging temptation. External equity, on the contrary, has no impact on the enforceability of relational contracts as the claims of outside shareholders scale down the principal's costs and benefits of honoring the relational contract to the same extent.

We develop a dynamic model where a risk-neutral principal relies on capital and effort of a risk-neutral agent to operate a firm. The agent might be a manager of the firm, but could also be its total workforce. The principal does not have sufficient internal funds to finance its investment projects and therefore needs external financing to get the firm running. Either debt or external equity (or a combination of both) can be used for that purpose. The respective financing modes have the following properties. Debt is issued on a competitive credit market, where the interest rate is determined endogenously, and creditors share the same discount factor as the principal. Equity can be sold to (prospective) shareholders at the beginning of the game, with the principal still retaining

\footnotetext{
${ }^{1}$ See Graham (2000), Graham and Leary (2011), or Strebulaev and Yang (2013), who argue that firms with no debt could generate tax benefits of up to $15 \%$ of the market value of equity by increasing leverage.

${ }^{2}$ For example, since 2010 it has always received an "Employees Choice Awards Best Place to Work", which is awarded by Glassdoor.com.

${ }^{3}$ In 2012, Southwest's debt-to-equity ratio was 0.48, compared to an industry ratio of 1.14; see Fool.com.
} 
control over all decisions made within the firm. But the principal can divert some of the firm's profits - and will do so if external equity is used - which comes at a cost for the firm. Therefore, the principal would, ceteris paribus, rather use debt than external equity.

Debt, however, is associated with indirect costs stemming from the principal's relationship with the agent. The agent has to be sufficiently incentivized to exert high effort. As effort includes nonverifiable elements like the agent's motivation or commitment towards the firm, relational contracts are required to provide incentives. Relational contracts only work if the agent expects to be compensated accordingly, which is the case if the firm's stakes in the cooperative relationship are sufficiently large. Those stakes are given by the difference between future profits with high effort and future profits with low effort - taking into account that once the principal reneges on payments promised to the agent, the latter will not exert high effort anymore. The difference between future profits with high and with low effort is determined by two aspects. First, generated per-period surplus is higher with high effort. Second, there is always the possibility that the firm goes bankrupt, and this event is more likely with low effort. However, creditors are not repaid in case of a bankruptcy, and consequently expected future payments to creditors go down if the principal reneges on the relational contract with the agent. As this reduction in expected payments to creditors (enjoyed off the equilibrium path) is larger for higher debt levels, more debt increases the principal's reneging temptation.

The exact mechanism depends on whether running the firm with low effort (i.e., after a deviation by the principal) is optimal. If this is the case, as in our baseline model, the firm is able to enjoy underpriced debt after a deviation. If running the firm with low effort is not optimal (we analyze this case in an extension of our model, in Section 7.3), the principal also defaults on the obligations to creditors upon reneging on the agent. Then, the firm's implicit arrangements with the agent and with creditors are more directly intertwined. More precisely, those arrangements are substitutes because the firm's commitment in each is given by its future rents; and larger supposed payments in one arrangement reduce the rents that can be used for the other.

External equity does not affect the enforceability of relational contracts since the interests between the principal and other shareholders remain aligned: Using external equity implies that the principal's payoffs are just downscaled. This downscaling affects all components that determine the relational contract, i.e., payments to the agent as well as continuation payoffs, to the same extent.

To sum up, low debt levels are, on average, associated with well-functioning relational contracts, and consequently more efficient principal-agent relationships. Given agents can pocket a fixed share of the resulting relationship surplus, they also are better off in this case.

Our model provides a novel explanation for why so many healthy and profitable firms have very little debt. ${ }^{4}$ This empirical fact cannot be explained by most traditional theories on capital structure choice. According to Graham and Leary (2011), traditional explanations are incomplete and new approaches are needed. Those should also consider the effect of a firm's financing structure on its relationship with non-financial stakeholders, for example employees. We are not the first to take this

\footnotetext{
${ }^{4}$ See Graham (2000), Graham and Leary (2011), or Strebulaev and Yang (2013).
} 
path, ${ }^{5}$ however basically all relevant agency theories have in common that debt only has a negative (marginal) impact on firm value if it is associated with a substantial and immediate bankruptcy risk. In our model, bankruptcy is a possibility, but merely an off-equilibrium phenomenon.

Closer related to the mechanism of our model, and to the argument that predictions of our model are relevant in situations in which we expect firms to rely more on long-term relations rather than short term contracts, there is evidence that leverage is generally low whenever issues like reputation and long-term commitment are crucial determinants of a firm's success. As mentioned before, Lincoln Electric is famous for having a highly motivated workforce. This is mainly attributed to its incentive system, with a large share of profits going to its employees. Since the incentive system not only includes the quantity and quality of work, but also dependability and cooperation (Hastings, 1999, p. 166), it provides a great example for the use of relational contracts. A failed international expansion in the late eighties forced Lincoln Electric to issue substantial debt for the first time in its history. According to former CEO Donald F. Hastings, this shocked employees who started to doubt that they could count on the firm keeping its promises in the future: "What we had not fully considered, however, was that the very fact of borrowing would be a major cultural shock to our employees. Most people at Lincoln saw the taking on of any debt as reckless, a view that had its roots in our incentive system [...]. As soon as it became apparent that we were going to have to borrow to finance the foreign expansion, employees became concerned. They could see it affecting their incomes. And, as our level of debt increased, they grew deeply worried - and they let senior managers know it." (Hastings, 1999, p. 166). ${ }^{6}$ Another piece of anecdotal evidence is Southwest Airlines. Southwest is known for treating its employees very well and employees are satisfied with their jobs. The debt ratio of Southwest is substantially lower than that of its competitors (according to Fool.com, Southwest's debt-to-equity ratio in 2012 was 0.48, while the ratios of Delta, US Airways, and United amounted to 7.42, 6.02, and 7.61, respectively.) Furthermore, while there have been almost 200 airline bankruptcies since $1978,{ }^{7}$ Southwest never had to face such difficulties.

More systematic evidence for an adverse impact of leverage on employee motivation is provided by Bae, Kang, and Wang (2011) and DeVaro, Kim, and Vikander (2014). The first study observes a negative connection between a firm's debt ratio and its popularity among employees, using several rankings that measure the latter aspect (including the Fortune Magazine's list of "100 Best Companies to Work For"). The second study shows that in case relational contracts are used to motivate CEOs, leverage has a negative impact on their performance and the bonus payments they receive.

Our theoretical results are derived in a setting that imposes a number of simplifying assumptions. In Section 7, we discuss some of these assumptions and show that our main results still hold if they are relaxed. First, note that if external equity is used, residual income is automatically distributed

\footnotetext{
${ }^{5}$ For example, Brander and Lewis (1986) emphasize the benefits of debt which can be used by firms as a negotiating tool in labor bargaining to demand larger concessions from its employees, an argument that has received empirical support by Matsa (2010) or Benmelech, Bergman, and Enriquez (2012). Other contributions in this direction are Berk, Stanton, and Zechner (2010), Titman (1984), or Maksimovic and Titman (1991).

${ }^{6}$ After getting back on track, Lincoln Electric quickly reduced leverage again, from a $63 \%$ debt-to-equity-ratio in 1992 to less than $12 \%$ in 1998, which allowed to "largely regain[...] the trust of its people". (Hastings, 1999, p. 178).

${ }^{7}$ See airlines.org.
} 
among all shareholders. We assume that those dividend payments, which are an indicator of the agent's effort, are not observable to outsiders and cannot be used as a base for formal contracts to incentivize the agent. In Section 7.1, we argue that this assumption has no effect on our results if we interpret the agent to be the firm's workforce as a whole rather than an individual player. Then, it generally is not possible to infer an individual agent's effort from total profits and therefore dividend payments - which would be needed to use the latter to provide incentives. Second, we assume that short-term debt is used and furthermore constant throughout. These assumptions are discussed in Sections 7.2 and 7.4. Whereas a decreasing debt-path might be optimal under some circumstances, having long-term debt would not affect our results. Rather, it would allow to relax a further assumption, namely that creditors are not able to detect the agent's effort, which is discussed in Section 7.5. Relaxing this assumption would also leave our results unaffected if auditing were not for free or did not allow to immediately detect any deviation, or if reneging on the relational contract would subsequently make it optimal to default on the firm's debt as well (Section 7.3).

Finally, we develop a number of extensions that provide additional arguments against debt financing. First, in Section 8.1, we show that external equity can also have a direct positive effect on the enforceability of relational contracts and not just be the residual financing mode. This effect is driven by the principal's ability to divert some of the firm's profits at the expense of external shareholders. For example, we let the firm's liquidation value be positive (Section 8.1.2). Then, the principal's "stealing" is only possible with respect to the firm's operating cash flows and not its liquidation value. Because a well-functioning relational contract reduces the firm's risk of going bankrupt, the principal now has extra incentives to honor the relational contract. These extra incentives are larger for lower debt levels, since less debt increases operating cash flows on the equilibrium path by more than it increases operating cash flows off the equilibrium path, i.e., upon reneging.

Second, in Section 8.2, we derive an additional commitment problem caused by debt financing. There, we assume that effort is continuous and that higher effort still increases the firm's survival probability. Then, debt creates incentives for the principal to reduce implemented effort (which creditors cannot observe), because this allows the firm to enjoy underpriced debt. In this case, the unconstrained first-best effort level cannot be implemented with any positive amount of debt.

\section{Related literature}

For many decades, the corporate finance literature has been concerned with the impact of a firm's financing structure on its value. Various benefits and costs have been attributed to the use of either debt or equity, where the most prominent ones can be subsumed under tax incentives and agency problems (see Harris and Raviv, 1991, or Myers, 2003, for reviews of the literature). Agency problems exist between firms and outside investors and are caused by the unverifiability of activities pursued by entrepreneurs or managers. Myers (1977), Stiglitz and Weiss (1981, 1983), or Holmstrom and Tirole (1997) develop moral hazard models to show that using too much debt can increase the bankruptcy 
risk. Because a firm is protected by limited liability, its downside risk after a default is reduced. This induces firms to take insufficient measures to reduce their bankruptcy risk, for example by selecting too risky investments or by enforcing inadequate effort to make projects successful. Bankruptcy costs or "costs of financial distress" constitute one part of the so-called tradeoff theory (Modigliani and Miller, 1963), which states that a firm's optimal debt ratio should balance the costs and benefits of debt. The latter are to a large extent associated with tax-deductible interest payments. ${ }^{8}$

However, the empirical case for the classical tradeoff theory is not too strong. ${ }^{9}$ It rather seems that actual debt levels are much lower than predicted, and firms with potentially low costs of financial distress seem to be substantially underleveraged (see Graham, 2000, among others). As Myers (2003, pp. 21) put it, "[...] studies of the determinants of actual debt ratios consistently find that the most profitable companies in a given industry tend to borrow the least [...] High profits mean low debt, and vice versa. But if managers can exploit valuable interest tax shields, as the tradeoff theory predicts, we should observe exactly the opposite relationship. High profitability means that the firm has more taxable income to shield, and that the firm can service more debt without risking financial distress." We show that even for healthy and profitable firms, where a bankruptcy is possible but merely an off-equilibrium phenomenon, using very little debt can be optimal because it helps firms to enforce relational contracts with their workforce.

We contribute as well to the literature on relational contracts. The theoretical foundations of this literature have been developed by Bull (1987), MacLeod and Malcomson (1989), or Levin (2003). A great review of the relevant contributions to this field (including more recent work) is provided by Malcomson (2013). Many economists now are convinced that the appropriate handling of relational contracts is crucial for the success of firms. Gibbons and Henderson (2013), for example, argue that different aspects of relational contracts are responsible for observed persistent performance differences among seemingly similar enterprises. Therefore, improving our understanding of the precise impact of relational contracts on firm success is crucial, in particular in the context of a firm's organizational structure. In this vein, this paper - among a few others (Hennessy and Livdan, 2009, Barron and Li, 2016, Englmaier and Fahn, 2016) - contributes to a better understanding of how a firm's investment and financial decisions can affect informal arrangements with its employees.

\footnotetext{
${ }^{8}$ In addition to providing tax benefits, debt is supposed to be a response to agency problems between a firm and its management. For example, managers might have tendencies to overinvest, which are potentially induced by preferences for empire building (see Williamson, 1964, or Jensen and Meckling, 1976), short-termism of managers who focus on activities the market can easily observe (see Stein, 1989, or Bebchuk and Stole, 1993), or managers' overconfidence into their own abilities (see Roll, 1986, or Heaton, 2002). If it is not possible to otherwise induce them to act in shareholders' interest, debt can optimally reduce the free cash flow available to managers and hence restrict their investment opportunities (see Jensen, 1986, Hart and Moore, 1995, or Zwiebel, 1996). In addition, debt shifts control rights to debtholders in bad states of the world. This threat of a potential loss of control is supposed to discipline managers and incentivize them to choose the right actions and repay investors (see Bolton and Scharfstein, 1990, Dewatripont and Tirole, 1994, Hart and Moore, 1998, or Inderst and Müller, 2003).

${ }^{9}$ This also holds for the (so-far-not-mentioned) pecking order theory by Myers and Majluf (1984). There, asymmetric information between a firm and outside investors concerning the real value of the firm induces a ranking over sources to finance new projects. First, internal funds should be used, followed by debt and then equity. Although this theory might explain the reluctance of firms to issue debt, the empirical evidence is at best mixed (see Leary and Roberts, 2010).
} 


\section{Model}

We analyze a firm and the behavior of its risk-neutral owner (principal, she) and a risk-neutral agent (he). In the following, we will - for the sake of concreteness - refer to a single agent, but the formal analysis and the main results are basically the same in a relationship between firm and total workforce (see Section 7.1). The firm needs two inputs for production: capital and the agent's effort. The capital investment needed to get the firm running exceeds the principal's own (internal) funds. Residual financing needs can be met by external equity or short-term debt. The time horizon is infinite and time is discrete. All parties (principal, agent, equity investors and creditors) share a common discount factor $\delta$, with $0<\delta<1$.

\subsection{Technology, financing and timing}

\subsubsection{Capital investment}

In period $t=0$, the principal has to make a capital investment $K>0$ to get the firm running (the amount $K$ is exogenously given). She has internal funds $I$, but $I<K$. Thus, she needs external sources to finance the remaining $K-I$. For that purpose, she can either use external equity or short-term debt.

To use short-term debt, she has to enter a perfectly competitive credit market at the end of every period $t=0,1,2, \ldots$. The total debt level borrowed in period $t-1$ and used in period $t$ is denoted by $D_{t}$, so that total equity amounts to $K-D_{t}$. Interest is denoted by $r_{t} D_{t}$ and paid at the end of period $t$, where $r_{t}$ is determined by an arbitrary creditor's zero-profit condition, taking into account that the credit market correctly assesses equilibrium play. Hence, the firm is supposed to repay $\left(1+r_{t}\right) D_{t}$ before it can enter the credit market at the end of period $t$ to borrow $D_{t+1}$. The principal is not able to divert $D_{t}$ after it has been borrowed, so $D_{t}$ is always invested into the firm. Repayment of $\left(1+r_{t}\right) D_{t}$ is specified in a credit contract, with a default leading to a liquidation.

If the principal intends to use external equity, she can sell a share $1-\theta$ of the firm's equity to outside investors at the beginning of the game, i.e. in period $t=0$. We rule out a market for the firm's equity in later periods. External shareholders are entirely passive, i.e., all decisions within the firm are made by the principal, and automatically receive a fixed share $1-\theta$ of the residual cash flows. Being the controlling shareholder, the principal is able to extract part of the firm's resources at the expense of external shareholders. The extraction of resources can happen through direct stealing (Shleifer and Vishny, 1997, Johnson et al., 2000) or be of a more indirect nature, for example if the principal conducts inefficient investments that generate private benefits (see Jensen and Meckling, 1976, Jenson, 1986).

Formally, we assume that the principal can steal a share $\beta_{t}$ of the firm's residual cash flow at the end of every period before the remainder is automatically distributed, where $\beta_{t} \leq 1$ can be freely chosen by the principal in order to maximize her payoff. Stealing is associated with relative costs $l\left(\beta_{t}\right)$ that have to be borne by the principal, where $0 \leq l\left(\beta_{t}\right) \leq 1, l^{\prime}>0, l^{\prime \prime} \geq 0$, and $l(0)=0 .{ }^{10}$

\footnotetext{
${ }^{10}$ Below, we will analyze the possibility that $l$ is not a function of the stolen share of the firm's residual cash flow,
} 
These costs might take the following form. If the principal conducts outright theft or fraud, this is illegal and, if detected, will be punished by law enforcement agencies. In this case, $l(\cdot)$ includes the probability of being caught and the subsequent (monetary or non-monetary) punishment (as in Shleifer and Wolfenzon, 2002, or Ellingsen and Kristiansen, 2011). If the extraction is not necessarily illegal, but for example happens through the expropriation of corporate opportunities from the firm by the principal (see Johnson et al., 2000, for specific examples), or through inefficient investments that generate private benefits to the principal (Shleifer and Vishny, 1997), $l(\cdot)$ represents the efficiency costs of these policies. Finally, $l(\cdot)$ might also include the principal's private effort costs of identifying and carrying out the best stealing opportunities.

Then, the principal keeps a total share $\left(1-l\left(\beta_{t}\right)\right) \beta_{t}+\left(1-\beta_{t}\right) \theta$ of the firm's residual cash flow, external shareholders effectively receive $\left(1-\beta_{t}\right)(1-\theta)$. $\beta_{t}$ is optimally chosen by the principal in every period and satisfies the first-order condition $\left(1-l\left(\beta_{t}\right)\right)-l^{\prime} \beta_{t}-\theta=0$. This yields a timeinvariant "stealing function" $\beta(\theta)$, with $\beta^{\prime}<0$ and $\beta(1)=0$, where the latter implies that no stealing occurs if only debt is used to meet the firm's need for external financing. We assume that for all $\theta \in[0,1],-\beta^{\prime}(\theta)(1-\theta)-(1-\beta(\theta))<0$. This means that the direct effect of a larger $\theta$ on external shareholder's payoffs (they receive a smaller share of the firm's residual cash flow) dominates the indirect effect (less stealing increases their effective share). In the following, we define $\lambda(\theta) \equiv(1-l) \beta(\theta)+(1-\beta(\theta)) \theta$ and assume $\beta(I / K)<1$, which implies that $\beta(\theta)<1$ if the firm uses no debt.

The market for the firm's equity is competitive, and in period $t=0$ the principal receives the discounted value of the cash flow that is expected to be distributed to (rational) shareholders, which we denote by $E$. Finally, we assume that if being indifferent, the principal uses internal funds.

\subsubsection{Production}

The firm needs the agent in order to produce. The principal makes an employment offer to the agent at the beginning of every period $t=1$. This offer involves a compensation package $\left(w_{t}, b_{t}\right)$, where $w_{t}$ is a fixed component paid at the beginning of the period and $b_{t}$ a discretionary bonus paid later. The agent's decision - whether to accept the offer or not - is captured by $d_{t}^{A} \in\{0,1\}$, where $d_{t}^{A}=1$ describes an acceptance and $d_{t}^{A}=0$ a rejection. If $d_{t}^{A}=0$, the firm is liquidated, with the consequences of a liquidation further described below. Whenever he is not employed, the agent consumes his outside utility $\bar{u} \geq 0$.

Upon accepting the contract $\left(d_{t}^{A}=1\right)$ and receiving $w_{t}$, the agent chooses his effort level. Effort is binary, $e_{t} \in\{0,1\}$, and associated with private effort costs $c\left(e_{t}\right)$, with $c(0)=0$ and $c(1)=c>0$. The agent's contribution to firm value is characterized by the function $f\left(e_{t}\right)$, with $f(1)>f(0) \geq 0$. We assume $f(1)-c>f(0)$, implying that effort yields a higher per-period surplus than no effort.

After observing $f\left(e_{t}\right)$, the principal has the choice to pay a bonus $b_{t}$ to the agent. The agent is supposed to be remunerated with this bonus whenever he has exerted the appropriate effort level.

The agent only accepts an employment offer that gives him a share of at least $1-\alpha$ of the total but of the absolute amount. 
relationship surplus in every period (with $0 \leq \alpha \leq 1$ ). For example, principal and agent could play a bargaining game in every period, determining the compensation package, effort choice, and desired continuation game, where bargaining weights of firm and agent are $\alpha$ and $1-\alpha$, respectively. ${ }^{11}$ The relationship surplus is the surplus generated by the relationship between firm and agent; the relationship between firm and providers of external capital is not taken into account. This implies that debt repayment as well as the principal's stealing does not reduce the relationship surplus. ${ }^{12}$

\subsubsection{Liquidation}

The firm may be liquidated in any period $t$, where a liquidation is an irreversible event. Three instances can trigger a liquidation of the firm: (i) the agent rejects the principal's employment offer; (ii) a shock that the firm can experience in every period; and (iii) a default on debt repayment.

The likelihood of a shock that yields a liquidation depends on the effort level in period $t$ and equals $1-\rho\left(e_{t}\right)$, with $\rho(1)>\rho(0) \geq 0$. Thus, high effort is not only beneficial because it gives a higher instantaneous surplus, but also because it increases the chances that the firm survives for another period. Without having a qualitative impact on our results, we will from now on impose

\section{Assumption 1: $\rho(1)=1$}

Assumption 1 implies that if the agent exerts high effort, the firm will not face an involuntary bankruptcy. In addition, we define $\rho \equiv \rho(0)<1$.

If the firm has not faced a negative shock, the principal is supposed to repay the loan $D_{t}$, plus interest $r_{t} D_{t}$. If she complies and repays, she enters the credit market again to borrow $D_{t+1}$, and the game moves on to the next period. If the principal defaults and refuses to repay, the firm is liquidated at the end of period $t$. We assume that the asset has no outside value. Hence, neither creditors nor equity holders get a share of outstanding obligations after bankruptcy. We relax this assumption in Section 8.1.2.

The timing of actions for each period $t \geq 1$ can be summarized in the following figure (where $\mathrm{P}$ denotes the Principal and A the Agent):

\footnotetext{
${ }^{11}$ Following Rubinstein (1982) and, in a dynamic setting, Halac (2015). Halac (2015) specifies a bargaining game over a similar compensation package where, at the beginning of every period $t$, principal or agent are assigned full bargaining power with probabilities $\alpha$ and $1-\alpha$, respectively. If there is no information asymmetry between principal and agent (as in our case), then such a bargaining game leads to the generalized Nash bargaining solution, where in each period the parties split the relationship surplus with shares $\alpha$ and $1-\alpha$. See also Miller and Watson (2013), for a more rigorous analysis of bargaining in a repeated game where formal contracts cannot be used.

${ }^{12}$ If interest payments or the principal's stealing reduced the surplus that is shared between principal and agent, the firm would have additional incentives to replace internal with external capital in order to reduce this surplus. This aspect is beyond the scope of our paper; Hennessy and Livdan (2009) analyze a situation where debt repayments reduce the bargaining surplus (of firm and workers) and find that this creates some benefits of debt financing.
} 


\begin{tabular}{cccc} 
A accepts $/$ rejects & $\begin{array}{c}\text { P can pay } \\
\text { bonus }\end{array}$ & $\begin{array}{c}\left(1+r_{t}\right) D_{t}(\text { re }) \text { paid } \\
\text { to creditor }\end{array}$ & $\begin{array}{c}\text { Decision } \\
\text { about }\end{array}$ \\
\hline $\begin{array}{l}\text { P offers } \\
\text { contract to } \mathbf{A}\end{array}$ & A supplies $e_{t}$ & $\begin{array}{c}\text { Bankruptcy } \\
\text { realized }\end{array}$ & $\begin{array}{c}\text { Default triggers } \\
\text { bankruptcy }\end{array}$
\end{tabular}

\subsection{Information structure}

We assume that effort $e_{t}$ as well as $f\left(e_{t}\right)$ can be observed by both principal and agent but not by any third party, in particular not by creditors. Therefore, neither $e_{t}$ nor $f\left(e_{t}\right)$ can be part of explicit, court-enforceable incentive contracts, and a relational contract is required to motivate the agent. Note that $f\left(e_{t}\right)$ is not called output in our setting but rather "reflects everything the principal values (gross of wages), (and) [...] might be more appropriately called the agent's total contribution" (Gibbons, 2010, p. 341). Therefore, the case $e=0$ does not necessarily imply that the agent does not work at all. It rather captures all dimensions of the agent's effort that are verifiable (and implemented optimally by the firm), either because they reflect standard tasks or because sufficient verifiable measures exist. Consequently, $f(0)>0$ is possible (and will generally be assumed throughout), implying that it can be profitable to run the firm with $e=0$.

The bonus payment $b_{t}$ is neither verifiable nor can it be observed by creditors. This is because the bonus does not only have monetary components, but includes aspects like promotions, extra free time, work climate, or other non-monetary perks the agent values and that are costly for the firm. Otherwise, payments might indicate to the credit market that a deviation from equilibrium behavior has occurred and trigger a respective adjustment of the interest rate, which is a case we want to rule out. For simplicity, we also assume that the fixed wage $w_{t}$ cannot be observed by creditors. ${ }^{13}$

Furthermore, although residual income is automatically distributed to all shareholders, those payments (and also the amount stolen by the principal) can neither be observed by creditors nor used in the arrangement between firm and agent. ${ }^{14}$

Because we assume external shareholders to be entirely passive (and because no market for the firm's equity exists in periods $t \geq 1$ ), we do not have to specify the degree of information they have access to.

A liquidation of the firm is observed by all players. To simplify the analysis, we assume that all aspects of the relationship between firm and creditors can be observed by the agent, as well as by the whole credit market as a whole.

\footnotetext{
${ }^{13}$ However, it would be sufficient to assume that the part of the compensation package used to reward the agent for his non-verifiable effort is not observable.

${ }^{14}$ This assumption is discussed in Section 7.1.
} 


\subsection{Equilibrium concept and selection}

Creditors are assumed to be passive. Yet they understand the game between principal and agent and can observe the firm's total debt. Therefore, the charged interest rate is set to A) satisfy a zero-profit condition, and B) take into account the relationship between the amount of debt and equilibrium effort (derived below).

The relationship between principal and agent, the only active players in this game, entails no private information. Therefore, our equilibrium concept is subgame perfect equilibrium. Our objective is to characterize a subgame perfect equilibrium that maximizes the expected discounted profit stream of the firm in period $t=0$, taking into account that the agent can keep a share $1-\alpha$ of the ongoing relationship surplus.

\subsection{Payoffs}

At the beginning of a period $t \geq 1$ in which the firm is operating, the expected equilibrium payoff of the principal (provided debt is repaid) can be defined recursively and equals

$$
\Pi_{t}=\lambda(\theta)\left[f\left(e_{t}\right)-w_{t}-b_{t}+\rho\left(e_{t}\right)\left(-D_{t}\left(1+r_{t}\right)+D_{t+1}\right)\right]+\rho\left(e_{t}\right) \delta \Pi_{t+1}
$$

Furthermore, since the investment $K$ has to be made in period $t=0$,

$$
\Pi_{0}=-\left(K-E-D_{1}\right)+\delta \Pi_{1},
$$

with $K-E-D_{1}=I$.

The agent's equilibrium payoff in a period $t \geq 1$ in which the firm is operating is

$$
U_{t}=w_{t}+b_{t}-c\left(e_{t}\right)+\delta\left[\rho\left(e_{t}\right) U_{t+1}+\left(1-\rho\left(e_{t}\right)\right) \bar{U}\right]
$$

where $\bar{U}=\frac{\bar{u}}{1-\delta}$.

\section{Benchmark cases}

Before deriving conditions for the enforceability of a relational contract to implement high effort, we analyze the optimal financing structure in two benchmark cases. There, without loss of generality, we let debt be constant in every period.

First, we characterize an equilibrium with zero effort (note that such an equilibrium always exists, also as a relational contract). If $f(0)$ is sufficiently large, it might then still be optimal to run the firm. As a second benchmark, we assume that formal contracts to enforce $e=1$ are feasible.

This section presents a summary of both cases. We relegate a more elaborate analysis, as well as the proofs of the presented Lemmas, to Appendix II. 


\subsection{Benchmark I: $e=0$}

Let us first characterize an equilibrium with $e=0$ in all periods, assuming that the firm has been started and the investment $K$ has been made. Recall that the principal needs the agent to operate the firm even if $e=0$. For this case to be interesting, $f(0)$ must be strictly positive and large enough so that running the firm is optimal.

An equilibrium with $e=0$ has the following features. The interest rate $r$ provided debt is expected to be repaid equals $r=(1-\delta \rho) / \delta \rho$, hence takes the possibility of a bankruptcy into account. The agent receives his outside option plus a share $1-\alpha$ of the net relationship surplus, which equals $(f(0)-\bar{u}) /(1-\delta \rho)$.

In addition, the continuation value of the firm must be larger than the interest payment, because otherwise a default would be optimal. This is captured by the condition $-\lambda(\theta) r D+\delta \Pi(0) \geq 0$, where $\Pi(0)=\lambda(\theta)[\alpha(f(0)-\bar{u})-\rho r D] /(1-\delta \rho)$. If this condition does not hold for $D=K-I$, the principal is credit constrained. This means that she might like to borrow more but is not granted additional credit, even if she were willing to pay a higher interest rate. Generally, driven by the assumption of limited liability, a voluntary default becomes more tempting for higher debt levels. This resembles the mechanism proposed by Myers (1977), Stiglitz and Weiss (1981, 1983), or Holmstrom and Tirole (1997). ${ }^{15}$ However, this aspect has been widely analyzed, and we aim at focussing on relatively healthy firms where owners have no incentives to take measures that induce a bankruptcy. We therefore assume that the negative (direct) effect of leverage on the principal's incentives is absent by assuming that a voluntary default is never optimal, i.e., we impose

Assumption 2: $\alpha \delta^{2} \rho \frac{f(0)-\bar{u}}{1-\delta \rho} \geq(K-I)$

Assumption 2 is sufficient for a voluntary default never to be optimal. It states that the principal has no incentive to default if she solely uses debt for her external financing needs. It does not affect our qualitative results, though, and we relax this assumption in Section 7.3.

The next Lemma gives the main result of this section.

Lemma 1: Given the firm has been started, and given $e_{t}=0$ in every period it is active, the firm only uses debt to meet its need for external financing, i.e., $D=K-I$.

Because we eliminate incentives for a voluntary default by imposing Assumption 2, the principal only uses debt financing. If the principal used external equity, she would steal a share $\beta(\theta)$ in every period. This would be anticipated by the providers of external equity who consequently would be willing to pay less for the firm's equity at the onset of the game. In sum, this would be costly for the principal because her rent-seeking activities are associated with costs $l(\beta)$. By reducing free cash-flow, debt serves as a commitment device for the principal to extract less rents, and hence

\footnotetext{
${ }^{15}$ There, limited liability induces highly leveraged firms to take insufficient measures to reduce their bankruptcy risk, for example by selecting too risky investments or by enforcing inadequate effort to make projects successful.
} 
increases her ex-ante profits (as in Jensen, 1986, Hart and Moore, 1995, or Zwiebel, 1996).

To simplify the subsequent analysis, we further assume that starting the firm in period $t=0$ is in any case optimal:

Assumption 3: $-K+[1-l(\beta(I / K)) \beta(I / K)] \delta \alpha \frac{f(0)-\bar{u}}{1-\delta \rho} \geq 0$.

Assumption 3 states that even if only external equity were used to finance the firm, and even if $e=0$ in every period, the firm's total expected profits are sufficient to cover the investment costs in period $t=0$.

\subsection{Benchmark II: Formal contracts feasible}

If formal contracts based on the agent's effort are feasible, the following contract can implement high effort in every period and allocate the relationship surplus accordingly. The agent receives the fixed wage $w=\alpha \bar{u}+(1-\alpha)(f(1)-c)$. If $e=1$, he also gets a bonus $b=c$, whereas no bonus is paid in case of $e=0$.

Lemma 2 characterizes the optimal financing structure when effort is verifiable.

Lemma 2: Assume the agent's effort is verifiable. Then, the firm is started and $e=1$ is implemented in every period. The firm only uses debt to meet its need for external financing, i.e., $D=K-I$.

The reluctance of the principal to use external equity is again driven by the associated efficiency loss induced by her rent-extraction activities. Furthermore, because effort is verifiable, the firm's financing structure has no effect on her ability to provide incentives for the agent. Therefore, the principal only considers the direct costs of her financing alternatives and favors debt over external equity.

\section{Relational contracts}

In the following we show that the financing structure affects the extent to which relational contracts can be enforced. We derive conditions for the enforceability of a relational contract with $d_{t}^{A}=1$ and $e_{t}=1$ in every period, and without a voluntary bankruptcy being optimal. The latter implies that the principal repays the firm's debt on the equilibrium path. Furthermore, we assume that debt is constant over time on and off the equilibrium path. ${ }^{16}$ Since the agent gets the share $(1-\alpha)$ of the total relationship surplus in every period, we can assume without loss of generality that wage and bonus are constant in every period. Hence, we can focus on stationary contracts and omit time subscripts in this section. We assume throughout that starting the firm is optimal. It will turn out, though, that this is generally the case given Assumption 3.

\footnotetext{
${ }^{16}$ We discuss the assumption of constant on-path debt in Section 7.2.
} 
Note that if high effort can be implemented on the equilibrium path, the agent's utility in this case equals $U(1)=\bar{U}+(1-\alpha) \frac{f(1)-c-\bar{u}}{1-\delta}$, whereas the principal gets $\Pi(1)=\lambda(\theta) \frac{[\alpha(f(1)-c-\bar{u})-r D]}{1-\delta}$. There, $\alpha(f(1)-c-\bar{u})-r D$ are the firm's per-period profits after meeting its obligations towards agents and creditors, and $\lambda(\theta)=[1-l(\beta)] \beta(\theta)+[1-\beta(\theta)] \theta$. Hence, the principal first extracts a share $\beta(\theta)$ of the firm's profits, where however efficiency $\operatorname{costs} l(\beta) \beta(\theta)$ reduce the amount the principal effectively pockets. The remaining profits are distributed accordingly, and shared between principal (getting $\theta$ ) and external shareholders (getting $(1-\theta)$ ). Both payoffs, $U(1)$ and $\Pi(1)$, are higher than the respective outside options, so principal and agent prefer to be part of the relationship.

Two conditions must hold in order to enforce high effort in every period. First, it must be optimal for the agent to choose high effort given that he expects to receive the bonus afterwards. Second, it must be optimal for the principal to pay the bonus after observing high effort. In order to characterize these constraints, we must state what happens after a deviation.

It is optimal to assume that a deviation triggers the harshest feasible punishment. ${ }^{17}$ Thus, we assume that if anyone deviates from the relational contract, all trust between parties is lost in the sense that the agent does not expect to receive the bonus anymore, and the principal does not expect the agent to exert effort in any future period. Therefore, if either the agent does not exert effort or the principal does not pay the bonus (after observing high effort), the equilibrium with zero effort will subsequently be played (which either involves a continuation of the firm with no effort, or a default and liquidation of the firm, whichever yields a higher payoff for the principal). ${ }^{18}$

The first condition - the agent needs sufficient incentives to deliver high effort - is captured by the agent's incentive compatibility (IC) constraint, which must hold in every period $t \geq 1$ :

$$
w+b-c+\delta U(1) \geq w+\delta(\rho \hat{U}(0)+(1-\rho) \bar{U}) .
$$

There, $\hat{U}(0)$ describes the agent's off-path continuation utility. It equals $\bar{U}+(1-\alpha) \frac{f(0)-\bar{u}}{1-\delta \rho}$ if the no-effort equilibrium is played after a deviation, and $\bar{U}$ if the principal subsequently decides to default.

For the principal, it must be optimal to make the promised payment $b$, given the agent has chosen high effort. This is captured by the so-called dynamic enforcement (DE) constraint, which is characterized by the next Lemma.

Lemma 3: The following condition must hold for the principal to pay the bonus b and repay the loan in every period:

$$
-\lambda(\theta) b+\delta(\Pi(1)-\hat{\Pi}(0)) \geq 0
$$

with $\hat{\Pi}(0)=\lambda(\theta)\left[\alpha \frac{f(0)-\bar{u}}{1-\delta \rho}-\frac{\rho r D}{1-\delta \rho}\right]$.

\footnotetext{
${ }^{17}$ Abreu (1988) shows that a player with an observable deviation from on-path behavior should be punished by receiving a minmax-payoff.

${ }^{18}$ Note that the following setting would yield the same outcome: A deviation by the agent $\left(e_{t}=0\right)$ does not affect continuation play. Instead, the agent is supposed to make an appropriate payment to the principal, where a failure to make this payment induces a shift to the zero-effort equilibrium.
} 
The proof of Lemma 3 can be found in Appendix I.

The (DE) constraint states that the difference between the principal's on- and off-path profits must be sufficiently high to cover the bonus payment. We furthermore have to take into account that the principal may or may not default after reneging on paying $b$. Lemma 3 implies that, after refusing to pay the bonus, the principal does not default and the firm is still operated (with zero effort, though). Note that we do not allow for an adjustment of the firm's debt after a deviation. But even if this were feasible, it would be optimal to stick to the firm's equilibrium borrowing policy after a deviation, for the following reason. After reneging, the principal would like to use the informational advantage she has over creditors concerning the firm's survival probability, and increase debt by as much as possible. This, however, would let the credit market infer that the game is not in equilibrium anymore. Then, the interest rate would be adjusted accordingly and take account of the fact that $e=0$ from then on. Without an adjustment, the principal can enjoy underpriced debt after a deviation, and off-path profits $\hat{\Pi}(0)$ are higher than $\Pi(0)$, the latter denoting the profits in an equilibrium with $e=0$ (as derived in Section 4.1).

Finally, in an equilibrium with $e=1$ in every period, the zero-profit condition yields an interest rate

$$
r=\frac{1-\delta}{\delta}
$$

\section{Optimal financing structure and the commitment role of equity financing}

We can now establish the link between capital structure choice and enforceability of relational contracts, and then characterize the optimal capital structure. First, we derive one integrated constraint that determines whether high effort can be enforced.

Lemma 4: For a given debt level $D$, high effort $e=1$ can be implemented in every period if and only if the following constraint is satisfied:

$$
-c+\delta \frac{f(1)-c-\bar{u}}{1-\delta}-\delta((1-\alpha) \rho+\alpha) \frac{f(0)-\bar{u}}{1-\delta \rho}-\frac{(1-\rho)}{(1-\delta \rho)} D \geq 0
$$

The proof of Lemma 4 can be found in Appendix I.

Adding (IC) and (DE) gives the (IC-DE) constraint, which is necessary and also sufficient for the enforceability of relational contracts. It states that effort costs today must not exceed the difference between future rents generated on the equilibrium path and future off-path rents (that is, with zero effort). These rents contain the whole firm's profits. Therefore, although the principal alone makes the decision whether to honor the relational contract and naturally only takes her own interests into 
account, the firm's total profits enter (IC-DE). This is because the claims of outside shareholders affect the principal's costs and benefits of honoring the relational contract to the same extent. She just receives a share $\lambda(\theta)$ of future firm profits in case she honors the relational contract, but her savings today when reneging on the bonus payment only amount to $\lambda(\theta) b$ as well. Therefore, the amount of external equity does not affect the principal's incentives in how to deal with the agent. ${ }^{19}$ This is different with debt financing, which is summarized in Proposition 1:

Proposition 1: Debt tightens the (IC-DE) constraint. Hence, more debt makes it more difficult to implement high effort. External equity does not affect the enforceability of high effort.

Proposition 1 immediately follows from Lemma 4. While external equity has no impact on the enforceability of relational contracts, the enforceability is negatively affected by debt. This negative effect is highlighted in (IC-DE), where a larger value of $D$ reduces the left-hand side. Intuitively, having debt reduces the principal's commitment in her relationship with the agent because the resulting repayment obligations reduce future profits on the equilibrium path by more than they reduce profits off the equilibrium path. After the principal reneged on paying the bonus, effort is zero in all subsequent periods. This increases the bankruptcy risk which does not, however, result in an appropriate adjustment of the interest rate, as creditors cannot observe the details of the relationship between principal and agent. The unadjusted interest rate is then too low to cover the real cost of capital. Therefore, higher debt makes the principal's outside option become relatively more attractive and increases her reneging temptation.

We should emphasize that the negative effect of debt on the enforceability of relational contracts does not rely on Assumption 2 (which states that a voluntary bankruptcy is not optimal off the equilibrium path). Assume that $f(0)=0$, so the principal would also default after refusing to pay the bonus. In this case, debt reduces on-path profits by more than off-path profits simply because it is repaid in the first, but not repaid in the second case. Thus, the negative effect of debt on the enforceability of relational contracts is unaffected by the exact specification of our model (see Section 7.3).

To conclude, reneging on the bonus payment subsequently reduces expected payments from firm to creditor. These "off-path savings" are larger for higher debt levels. Hence, more debt increases the principal's reneging temptation.

Before deriving the conditions for an optimal capital structure, we impose

$$
\text { Assumption 4: } \frac{(f(1)-c-\bar{u})(1-l(\beta(I / K)) \beta(I / K))}{1-\delta} \geq\left(\frac{f(0)-\bar{u}}{1-\delta \rho}\right) .
$$

Assumption 4 compares two cases: profits when high effort can be enforced but only external equity is used (left-hand side), with profits when only debt is used but zero effort is implemented (right hand side). It states that implementing high effort is more important than the efficiency losses from

\footnotetext{
${ }^{19}$ This changes in Section 8.1.
} 
the rent-extraction activities of the principal.

Proposition 2: The firm's optimal structure of external financing, $D^{*}$ and $E^{*}$, is characterized by one of the following cases:

- $e=1$ can be enforced for maximum debt $D=K-I$, or can not be enforced for $D=0$. In both cases, $D^{*}=K-I$ and $E^{*}=0$.

- Otherwise, $D^{*} \in[0, K-I]$, and given by the binding (IC-DE) constraint; furthermore, $E^{*}=$ $K-I-D^{*}>0$.

The proof of Proposition 2 can be found in Appendix I.

Generally, the principal would prefer to use debt rather than external equity, because the latter is associated with direct costs due to the efficiency loss of stealing. Debt, however, has a negative effect on the enforceability of relational contracts.

Proposition 2 implies that values of $f(1)$ and $\overline{f(1)}$ exist such that the debt level is irrelevant for the enforceability of relational contracts for $f(1)<\underline{f(1)}$ and $f(1)>\overline{f(1)}$. In the first case, relational contracts can never be enforced, in the latter they can always be enforced. Hence, $D=K-I$ in this case, because only the direct costs of external equity have to be taken into account. For $\underline{f(1)} \leq f(1) \leq \overline{f(1)}$, there exist thresholds $D(f(1))$, with $D(f(1)) \leq K-I$, determined by the binding (IC-DE) constraint, such that relational contracts are enforceable for $D \leq D(f(1))$, and not for $D>D(f(1))$. Thus, debt in this case is determined by the binding (IC-DE) constraint. This is because of Assumption 4 which states that the efficiency costs of using external equity are lower than the gains from a well-functioning relational contract.

\section{Discussion of assumptions}

In this section, we discuss a number of assumptions that we have imposed in order to simplify the preceding analysis. We can show, though, that relaxing these assumptions does not make the negative effect of debt financing on relational contracts disappear.

\subsection{Verifiable dividend payments and multilateral relational contracts}

If external equity is used to finance the firm, residual income is automatically distributed among all shareholders. We assume that those dividend payments - which are an indicator of the agent's effort - cannot be observed by outsiders. This implies that dividend payments can neither be used in credit arrangements nor as a basis for a (formal) contract with the agent; if formal contracts based on $y$ were feasible, the firm would not need relational contracts to motivate the agent. This assumption helps to streamline the exposition of the model but is arguably rather strong. However, it is not essential for our results if we regard the agent not as an individual player but as the firm's 
total workforce. The reason is that the contribution of an individual agent to total profits, and thus dividend payments, can generally not be assessed.

Assume that the task of the principal is to manage the workforce of the firm. This workforce is of mass 1 , and each of the individual agents chooses effort $e_{t} \in\{0,1\}$ in every period. While $e=1$ is associated with effort $\operatorname{cost} c, e=0$ is not costly for the respective agent. The

contribution of the workforce to firm value amounts to $f(y)$, where $y=\int_{0}^{1} e_{i} d i, i$ denotes an individual agent (hence, $y=1$ if all agents choose high effort), and $f(y)$ is strictly increasing and concave. Furthermore, dividend payments to external shareholders in a given period amount to $(1-\beta(\theta))(1-\theta)[\alpha(f(y)-c \cdot y-\bar{u})-r D]$. Since $\theta$ is common knowledge, the size of a dividend payment can be used to infer $y$. Now, assume that both, formal contracts based on $y$ as well as multilateral relational contracts (Levin, 2002), are feasible. The latter implies that the behavior of the firm towards one particular agent can be observed by all other employees. For this reason, reneging on one agent can (and optimally will) be punished by all of them. They subsequently lose trust and are not willing to exert effort anymore. Then, using formal contracts based on $y$ cannot be used to motivate any agent. Because of the law of large numbers, the size of $y$ is unaffected by an individual agent's effort. Put differently, by just observing $y$, one cannot assess whether a specific agent exerted effort or not. This outcome resembles the situation in most firms with a considerable amount of employees, whose contributions will be impossible to link to profits.

The optimal multilateral relational contract is basically identical to the one with one agent, as derived above. If we only consider symmetric equilibria (i.e., either all agents choose $e_{t}=1$, or none of them does), the formal analysis is completely identical. If we also allow for non-symmetric equilibria, the situation is similar to the one where we allow for continuous effort, as analyzed in Section 8.2. If the (IC-DE) constraint binds, relational contracts can only be enforced for a subset of agents, and the number of those agents is maximized for low debt.

If creditors can observe $y$, they are able to detect deviations and subsequently adjust interest rates accordingly. However, we show below that in this case the negative effect of debt financing on relational contracts remains if either $f(0)$ is so small that non-payment of $b$ is optimally followed by a default (Section 7.3), if only long-term debt can be used (Section 7.4), or if auditing the firm's performance is costly or does not imply an immediate detection of a firm's deviation (Section 7.5).

\subsection{Non-constant debt}

We assume that debt is constant on the equilibrium path. This assumption is not without loss of generality in cases where the optimal debt level is determined by the binding (IC-DE) constraint. More precisely, assume there is a debt level $\bar{D}<K-I$, such that the (IC-DE) constraint holds for $D \leq \bar{D}$ but not for $D>\bar{D}$. With constant debt, it would be optimal to set $D=\bar{D}$ and finance the remainder with external equity (see Proposition 1), which is associated with an efficiency loss.

Alternatively, the principal could start with a debt level above $\bar{D}$ and use retained earnings in order to reduce its debt level and replace it with internal equity. This would imply that zero effort was implemented for the first few periods, and - conditional on the firm surviving - effort could 
only jump to 1 after leverage was reduced to a level below $\bar{D}$. Such a strategy would be optimal if the output loss of having zero effort for a couple of periods would be lower than the efficiency loss caused by rent extraction activities when the share of external equity was high. ${ }^{20}$

Such considerations would also drive players' behavior in case the firm faced a liquidity shock forcing it to temporarily take on some debt (as in the Lincoln Electric example described in the Introduction). Assume the firm faced such a shock with a small probability at the beginning of every period. If the resulting debt level was too high to still satisfy the (IC-DE) constraint, the firm would not be able to implement high effort for a couple of periods until enough debt was repaid. In this case, one would also have to consider the possibility of cash holdings as a precautionary device to address the liquidity shock (and further work out what happens if debt approaches a level where a continuation of the firm would not be profitable anymore). Nevertheless, behavior would still be driven by the main mechanism derived in this paper: debt makes it more difficult to implement relational contracts.

\subsection{Assumption 2 does not hold - low $f(0)$}

In the following we will show that relaxing Assumption 2, which states that a voluntary default is never optimal and the firm is hence not credit constrained, has no qualitative impact on our results, but rather strengthens them. We relax Assumption 2 by reducing $f(0)$ and, for convenience, focus on the case $f(0)=0$. This implies that the firm is not run if no effort can be implemented, and that once the principal decides to renege on the bonus payment, she will consequently also default. The dynamic enforcement constraint becomes $-b-r D+\delta \frac{[\alpha(f(1)-c-\bar{u})-r D]}{1-\delta} \geq 0$, the agent's incentive compatibility constraint is $-c+b+\delta\left(\bar{U}+(1-\alpha) \frac{f(1)-c-\bar{u}}{1-\delta}\right) \geq \bar{U}$, where we must also take into account that the firm is liquidated after the agent decides to not exert effort. Combining both constraints and noting that $r=(1-\delta) / \delta$ implies the following condition, which is necessary and sufficient to enforce high effort:

$$
-c+\delta \frac{f(1)-c-\bar{u}}{1-\delta}-\frac{D}{\delta} \geq 0 .
$$

As before, debt has a negative effect on the enforceability of relational contracts, only the marginal negative effect is larger. This is mainly because debt is only repaid on the equilibrium path and reduces future on-path profits. The intuition for the negative effect of debt has slightly changed. Before, the resulting consequence of having underpriced debt made it more tempting for the principal to renege when leverage was high. Now, the two implicit arrangements the firm has (one with the agent and one with a creditor) are more directly intertwined. Both will only be honored if future profits are sufficiently high, but those future profits can only be used once. This means that both arrangements are substitutes, and larger supposed payments in one arrangement reduce the firm's commitment in the other.

\footnotetext{
${ }^{20}$ For a more detailed analysis of a related case, see Barron and Li (2015), who show that if a firm uses external financing, it might optimally first meet its financial obligations at the expense of having low compensation and effort levels for a couple of periods.
} 
Note that having $f(0)=0$ would also allow to relax our assumption that creditors cannot detect deviations in the principal-agent relationship. Since the principal would immediately default after reneging on the bonus, creditors would have no opportunity to appropriately respond to such a deviation.

\subsection{Long-term debt}

We assume that the firm enters the credit market in every period. Old debt (plus interest) has to be repaid before the firm can borrow again. Since debt is constant, though, the firm effectively pays $r D$ in every period. If the credit contract had a longer duration than just one period, the outcome would therefore exactly be the same (if designing the credit contract was costly, the optimal duration would naturally be longer). Furthermore, as in the situation where $f(0)=0$, our assumption that creditors have no information regarding the relationship between principal and agent could be relaxed. If creditors were able to observe deviations, it would take until the maturity of a credit contract before they could adjust the terms appropriately and demand a higher interest rate. This is an aspect we further pursue in the next paragraph.

\subsection{Creditor can audit past performance}

As pointed out before, our assumption that creditors are not able to detect deviations in the principalagent relationship can be relaxed if the model setup is slightly adjusted. Generally, one might argue that creditors should have the possibility to demand auditing of the previous performance of the firm and eventually find out about deviations. We can show that even within our main setup, giving the creditor the opportunity to audit the firm does not make the negative effect of debt on relational contracts vanish, unless this auditing is (almost) for free and helps to detect a deviation immediately.

Assume that auditing is for free, but that it takes the creditor $T \geq 0$ periods until a deviation is detected (note that this case is formally equivalent to having no delay in auditing but longterm credit contracts which last for $T+1$ periods). Then, upon a deviation in some period $t$, the principal still pays an interest rate of $(1-\delta) / \delta$ for the next $T$ periods, and only from period $t+T+1$ onwards, interest is adjusted to $(1-\delta \rho) / \delta \rho$. The principal's continuation profits after reneging on

her bonus obligations are $\hat{\Pi}(0)=\lambda(\theta)\left[\alpha\left(\frac{f(0)-\bar{u}}{1-\delta \rho}\right)-\rho D\left(\frac{1-\delta}{\delta} \frac{1-\delta^{T} \rho^{T}}{1-\delta \rho}+\delta^{T-1} \rho^{T-1}\right)\right]$, yielding the (DE) constraint

$$
-c+\delta \frac{f(1)-c-\bar{u}}{1-\delta}-\delta(\alpha+(1-\alpha) \rho) \frac{f(0)-\bar{u}}{1-\delta \rho}-D \frac{(1-\rho)\left(1-\delta^{T} \rho^{T}\right)}{(1-\delta \rho)} \geq 0 .
$$

Thus, only if $T=0$, debt does not have a negative impact on the enforceability of relational contracts. Otherwise, debt still tightens the (DE) constraint, and this effects becomes stronger, the longer it takes for the creditor to detect a deviation.

Assume that $T=0$, but that auditing is costly. These costs would have to be borne by the firm because creditors make zero profits. Then, if the dynamic enforcement constraint was binding in our main setting (otherwise, auditing would not be needed), the principal would have the choice to 
either stick to the resulting debt level (without monitoring), or to increase leverage to $K-I$ (with monitoring). The latter case would be optimal if auditing costs were small compared to $l(\beta)$.

\subsection{Renegotiation after default}

We assume that once the principal defaults on repaying the debt (which does not happen on the equilibrium path), the firm is liquidated and creditors are left with nothing. One might argue, however, that instead of a liquidation, creditors could respond to a default by overtaking the firm and installing a new manager/principal. It is straightforward to show that the incentives of the principal would not be affected by this possibility, at least if the principal was not able to participate in future profits generated by a continuation of the firm. Then, her payoff after a default would still be zero, and she would take exactly the same decisions as in our setting.

\section{Extensions}

In this section, we show that the negative impact of debt on the enforceability of relational contracts becomes more pronounced once the model is extended along a number of lines. In the following, we simplify the analysis by assuming $\alpha=1$.

\subsection{The commitment role of external equity financing}

External equity has a direct negative impact on profits but does not affect the enforceability of relational contracts. This is because the associated consequences cancel out in the (IC-DE) constraint. Therefore, external equity is potentially preferred because of the drawbacks associated with debt financing. In this section, we show that external equity not only serves as the residual external financing mode to avoid the negative effect of debt on commitment, but can even have a direct positive effect. The reason is that, although stealing is costly, it might provide additional incentives for the principal to honor the relational contract. The principal is only able to steal as long as the firm exists, and therefore the agent's effort can create an additional private benefit for the principal because it increases the firm's survival probability.

There, note that generally one might expect the possibility of stealing to reduce the cash invested into the firm, thereby increasing the firm's bankruptcy risk and consequently the interest rate. Although we do not explore this particular aspect within our model, this section develops an argument for an opposite effect: Because her stealing opportunities increase the principal's incentives to honor the relational contract, and because only this secures a low bankruptcy risk via high effort, the possibility of stealing actually reduces the interest rate if high effort cannot be implemented otherwise. $^{21}$

\footnotetext{
${ }^{21}$ We thank an anonymous referee for bringing up this point.
} 


\subsubsection{Different functional form of $l$}

We have assumed that $l$ - the cost of stealing - is a function of the stolen share, $\beta$. This substantially simplifies our analysis since the principal's total share of residual cash-flows cancels out in the (ICDE) constraint, and external equity does not affect the enforceability of the relational contract. In many cases, though, $l$ might rather be a function of the stolen amount. For example, if $\beta$ relates to inefficient investments that yield private benefits, the associated efficiency loss should rather relate to the absolute size of such an investment and not to the size relative to the firm's residual cash flow. In this section, we show that if $l$ is a function of the stolen amount, debt still negatively affects the enforceability of relational contracts. Moreover, using external equity has a direct positive effect. Using external equity makes the principal steal part of the firm's cash flow. This, however, is only possible as long as the firm exists, which is more likely if the agent exerts effort. Therefore, the principal has an additional incentive to honor the relational contract in order to secure her stealing opportunities in the future.

We denote the stolen amount by $S$, and hence have $l(S)$, with $l^{\prime}>0, l^{\prime \prime} \geq 0$ and $l(0)=0$. Then, the principal's total payoff in a period with high effort amounts to $[1-l(S)] S+\theta[(f(1)-c-\bar{u})-r D-S]$, and $[1-l(S)] S+\theta[(f(0)-\bar{u})-\rho r D-S]$ in a period with low effort. The optimal $S$ is the same in both cases and characterized by $[1-l(S)]-l^{\prime} S-\theta=0$, which yields an optimal "stealing function" $S(\theta)$, with $S^{\prime}=1 /\left(-2 l^{\prime}-l^{\prime \prime} S\right)<0 .{ }^{22}$ As before, we also assume that the direct effect of a larger $\theta$ on external shareholders' payoffs (they receive a smaller share of the firm's residual cash flow) dominates the indirect effect (a lower $S$ increases their effective share), so that for all $\theta \in[0,1]$ and all $D \in[0, K-I],[(f(1)-c-\bar{u})-r D-S(\theta)]+(1-\theta) \frac{d S^{*}}{d \theta}>0$, which yields $d \theta / d D>0 .{ }^{23}$

Now, the (IC-DE) constraint becomes

$$
-c+\delta \frac{f(1)-c-\bar{u}}{1-\delta}-\delta \frac{f(0)-\bar{u}}{1-\delta \rho}-D \frac{1-\rho}{1-\delta \rho}+\frac{1-l-\theta}{\theta} S \frac{\delta^{2}(1-\rho)}{(1-\delta)(1-\delta \rho)} \geq 0 .
$$

In order to find out about the effect of the firm's financing structure on the enforceability of relational contracts, we compute the derivative of the left-hand side of the constraint with respect to $D$. Using the condition for the principal's optimal $S,[1-l(S)]-l^{\prime} S-\theta=0$, this derivative boils down to

$$
-\frac{1-\rho}{1-\delta \rho}-\frac{d \theta}{d D} \frac{S(\theta)[1-l(S)]}{\theta^{2}} \frac{\delta^{2}(1-\rho)}{(1-\delta)(1-\delta \rho)} .
$$

The first term captures the direct negative effect of debt financing on the enforceability of relational contracts (as analyzed above). The second term captures the effect of a less extensive use of external equity $(d \theta / d D>0)$. Less external equity reduces $S(\theta)$. Although this directly increases the principal's profits at the onset of the game $(l(\cdot)$ goes down), it tightens the (IC-DE)

\footnotetext{
${ }^{22}$ Here, we make the implicit assumption $S(\theta)<f(0)-\bar{u}-r D$ for all $\theta \in[0,1]$ and all $D \in[0, K-I]$ in order to guarantee an interior solution.

${ }^{23} \theta$ is obtained by setting $K-I-D=\delta \Pi^{E}(e), \Pi^{E}(e)=\frac{(1-\theta)\left[\alpha(f(1)-c-\bar{u})-r D-S^{*}\right]}{1-\delta}$, which yields $\frac{d \theta}{d D}=$ $\frac{1-\delta}{\delta\left[(f(1)-c-\bar{u})-r D-S^{*}\right]+\delta(1-\theta) \frac{d S^{*}}{d \theta}}$.
} 
constraint, for the following reason. Ex post, stealing increases the principal's profits, but only as long as the firm exists. Therefore, a smaller share of external financing reduces the principal's stakes, that is, the amount she is bound to lose after a bankruptcy. Consequently, her benefits from honoring the relational contract and paying the bonus go down.

This discussion indicates that it might actually be optimal to also replace internal with external equity, in case high effort cannot be implemented for $E=K-I$. Then, however $\theta$ must remain sufficiently large to make sure the principal still is the controlling shareholder.

\subsubsection{Asset with positive outside value}

Here, we assume that the resale value of the firm's asset is not zero anymore. More precisely, upon a liquidation of the firm, the amount $\gamma K$, with $\gamma<1$, is realized. This liquidation value is immediately realized ${ }^{24}$ and allocated among principal, external shareholders and creditors in the following way. The rights of the creditors are senior and they receive $\bar{D} \equiv \min \{D(1+r), \gamma K\}$ in case of a liquidation. The remainder, $\max \{\gamma K-D(1+r), 0\}$, is allocated among shareholders, where external shareholders collect a share $1-\theta$, and $\bar{\Pi} \equiv \theta \max \{\gamma K-D(1+r), 0\}$ goes to the principal. Thus, the principal is not able to steal from the liquidation value before the remainder is allocated appropriately. This is because the principal is only able to use her role as controlling shareholder to divert some of the firm's operating income while the firm is running. After a bankruptcy, the situation fundamentally changes, and external trustees take over in order to liquidate the firm. As in the previous section, this gives the principal an extra benefit of keeping the firm alive and consequently increases her incentives to honor the relational contract if more external equity is used.

Now, the (IC-DE) constraint equals $-\lambda(\theta) c+\delta \Pi(1) \geq \delta \hat{\Pi}(0) .{ }^{25}$ We also impose the simplifying assumption $l(\beta)=\beta$, which implies $\beta=\frac{1-\theta}{2}$ and $\lambda(\theta)=\left(\frac{1+\theta}{2}\right)^{2}$. Then, the (IC-DE) constraint becomes

$$
-c+\delta \frac{f(1)-c-\bar{u}}{1-\delta}-\delta \frac{f(0)-\bar{u}}{1-\delta \rho}-D \frac{1-\rho}{1-\delta \rho}-\frac{\delta(1-\rho)}{1-\delta \rho} \frac{\theta}{\left(\frac{1+\theta}{2}\right)^{2}} \max \left\{\gamma K-\frac{D}{\delta}, 0\right\} \geq 0 .
$$

We have to distinguish between the two cases $D \leq \delta \gamma K$ (the creditor is fully reimbursed after a liquidation) and $D>\delta \gamma K$ (the creditor is not fully repaid). Starting with the second case, $D>\delta \gamma K$ implies that $\bar{\Pi}=0$, and the constraint becomes $-c+\delta \frac{f(1)-c-\bar{u}}{1-\delta}-\delta \frac{f(0)-\bar{u}}{1-\delta \rho}-D \frac{1-\rho}{1-\delta \rho} \geq 0$. This is equivalent to condition (IC-DE), the (IC-DE) constraint derived above; so for $D>\delta \gamma K$, debt has exactly the same effect on the enforceability of relational contracts as before.

\footnotetext{
${ }^{24}$ In an earlier version of the paper (see Fahn et al., 2014), we show that a later realization of the liquidation value further amplifies the commitment role of equity financing.

${ }^{25}$ Taking into account that Assumption 2 is adjusted accordingly to make sure that a voluntary default is not optimal if the outside value of assets is positive (and debt is fully repaid off the equilibrium path).
} 
For $D \leq \delta \gamma K$, the (IC-DE) constraint becomes

$$
-c+\delta \frac{f(1)-c-\bar{u}}{1-\delta}-\delta \frac{f(0)-\bar{u}}{1-\delta \rho}-\frac{1-\rho}{1-\delta \rho}\left(\frac{D\left(\frac{1-\theta}{2}\right)^{2}+\theta \delta \gamma K}{\left(\frac{1+\theta}{2}\right)^{2}}\right) \geq 0 .
$$

Again, we compute the derivative of the constraint's left-hand side with respect to $D$, and obtain

$$
-\frac{1-\rho}{1-\delta \rho}\left(\frac{(1-\theta)^{2}}{(1+\theta)^{2}}+\frac{1-\theta}{2} \frac{\delta \gamma K-D}{\left(\frac{1+\theta}{2}\right)^{3}} \frac{d \theta}{d D}\right)
$$

Since $d \theta / d D>0,{ }^{26}$ the constraint also is tightened for larger values of debt if $\delta \gamma K-D>0$. As in the previous section, the reason is that the principal can steal a share $\beta$ of the firm's free cash flows only as long as it operates. The fact that she only gets a share $\theta$ of the liquidation value (compared to the share $\lambda>\theta$ she can keep from the operating cash flow) provides an additional incentive to honor the relational contract, and this additional incentive is more pronounced for lower debt levels. As long as $\bar{\Pi}>0$, less debt increases the firm's total on- and off-path continuation profits (i.e., the respective weighted sums of operating cash flows and liquidation value) to the same extent. However, the firm's expected operating cash flows on the equilibrium path are increased by a larger amount than expected operating cash flows off the equilibrium path. Therefore, less debt raises the difference between the amounts the principal can steal in both states, giving rise to an additional benefit of having low debt when it comes to the enforceability of relational contracts.

\subsection{Debt financing and additional commitment problems}

In this section, we show that debt financing might also create incentives for principal and agent to collude at the expense of creditors. ${ }^{27}$ Thereby, we relax the assumption of binary effort and instead assume effort is continuous. Moreover, higher effort not only increases output, but also the firm's survival probability. In this case, debt still restricts the effort level that can be enforced within a relational contract. But debt also creates incentives for the principal to reduce implemented effort without creditors knowing it, because this allows the firm to enjoy underpriced debt. Then, the unconstrained first-best effort level cannot be implemented with any debt.

Formally, we extend the model along the following lines. Effort is continuous, $e_{t} \in[0, \bar{e}]$, with $\bar{e}$ large enough, effort costs are $c \cdot e_{t}$, and the contribution of the agent is $g\left(e_{t}\right)$, with $g(\cdot)$ strictly increasing and concave. Furthermore, we assume that $\rho(\bar{e})<1$, as well as $\rho^{\prime}>0$ and $\rho^{\prime \prime} \leq 0$. In addition, $\rho(0)<1$ and $g(0)$ are sufficiently large to satisfy Assumption 2.

First, we characterize the unconstrained first-best effort level $e^{F B} \cdot e^{F B}$ not only maximizes the per-period surplus $g(e)-c \cdot e-\bar{u}$, but also considers the positive effect of effort on the firm's survival probability. Hence, $e^{F B}$ is characterized by

\footnotetext{
${ }^{26}$ Recall that $\theta$ is characterized by $\Pi^{E}(e)=(1-\beta(\theta))(1-\theta) \frac{\alpha(g(e)-c \cdot e-\bar{u})-r D}{1-\delta}$, and $E=K-I-D=\delta \Pi^{E}(e)$. Furthermore, using $l(\beta)=\beta$, and $\beta=\frac{1-\theta}{2}$, yields $\frac{d \theta}{d D}=\frac{\left(1+\theta^{2}\right)(1-\delta)}{2 \delta \theta(\alpha(g(e)-c \cdot e-\bar{u})-r D)}>0$.

${ }^{27}$ We thank an anonymous referee for bringing up this aspect.
} 


$$
\left(g^{\prime}-c\right)\left(1-\delta \rho\left(e^{F B}\right)\right)+\delta \rho^{\prime}\left(g\left(e^{F B}\right)-c e^{F B}-\bar{u}\right)=0
$$

Furthermore, if all enforcement problems are left aside, the costs induced by the principal's stealing activities still make it optimal to entirely use debt financing. ${ }^{28}$

In a next step, we characterize the conditions an equilibrium effort level $e^{*}$ must satisfy. As before, there is an (IC-DE) constraint, which equals

$$
-c e^{*}+\delta \rho\left(e^{*}\right)\left[\frac{g\left(e^{*}\right)-c e^{*}-\bar{u}}{1-\delta \rho\left(e^{*}\right)}-\frac{g(0)-\bar{u}}{1-\delta \rho(0)}\right]-D \frac{\rho\left(e^{*}\right)-\rho(0)}{1-\delta \rho(0)} \geq 0,
$$

taking into account $r\left(e^{*}\right)=\left(1-\delta \rho\left(e^{*}\right)\right) / \delta \rho\left(e^{*}\right)$.

If this constraint binds, debt has a negative impact on the enforceability of relational contracts. Then, a higher debt level reduces implementable effort, for the same reasons as before. The optimal financing structure balances the direct benefits of using debt (lower stealing costs) with the indirect costs (less implementable effort and consequently higher bankruptcy risk).

Given such an equilibrium, in particular if (IC-DE2) allows for high effort levels even withw high debt (for example, if the IC-DE2 constraints hold for $e^{F B}$ and $D=K-I$, it seems optimal to only use debt financing), principal and agent might have an incentive to collude at the expense of creditors: For a perceived equilibrium effort level $e^{*}$ and the associated interest rate $r\left(e^{*}\right)$, it can be optimal for the firm to agree with the agent to reduce effort. This reduces the firm's output, but also lets the firm enjoy underpriced debt - because the interest rate is based on the bankruptcy risk induced by $e^{*}$ (recall that a creditor cannot observe the agent's real effort level), whereas the actual bankruptcy risk is higher.

Formally, for an equilibrium effort level $e^{*}$ and the associated interest rate $r\left(e^{*}\right)$, the firm's profits are

$$
\frac{g(e)-c e-\bar{u}-\rho(e) r\left(e^{*}\right) D}{1-\delta \rho(e)} .
$$

Therefore, the profit-maximizing, "collusion-proof" effort level $\tilde{e}$, given an interest rate $r\left(e^{*}\right)$, is characterized by

$$
\left(g^{\prime}-c\right)(1-\delta \rho(\tilde{e}))+\rho^{\prime} \delta(g(\tilde{e})-c \tilde{e}-\bar{u})-\rho^{\prime} r\left(e^{*}\right) D(1+\delta \rho(\tilde{e}))=0
$$

Comparing conditions 1 and 2 reveals that $\tilde{e}<e^{F B}$. Therefore, if $e^{*}$ is sufficiently close to $e^{F B}$ and if debt is used, the principal has an incentive to implement a lower effort level at the creditor's expense. Furthermore, comparing conditions 1 and 2 indicates that $e^{F B}$ cannot be enforced with any positive debt level. Generally, more debt reduces collusion-proof effort, ceteris paribus. Because these considerations are anticipated by creditors, the interest rate is adjusted accordingly and the firm has to bear additional costs of external financing.

\footnotetext{
${ }^{28}$ For any equilibrium effort $e^{*}$ and an arbitrary debt level $D$, the principal's profits at the beginning of the game are $\Pi_{0}\left(e^{*}\right)=-K+l(\beta(\theta)) \beta(\theta) D+\delta[1-l(\beta(\theta)) \beta(\theta)] \frac{(g(e)-c \cdot e-\bar{u})}{1-\delta \rho\left(e^{*}\right)}$, taking into account that $r\left(e^{*}\right)=\frac{1-\delta \rho\left(e^{*}\right)}{\delta \rho\left(e^{*}\right)}$. Hence, $\partial \Pi_{0}(0) / \partial D>0$, which yields $\Pi_{0}\left(e^{*}\right)=-K+\delta \frac{g\left(e^{*}\right)-c \cdot e^{*}-\bar{u}}{1-\delta \rho\left(e^{*}\right)}$, provided no external equity is used.
} 
To conclude, equilibrium effort is not only restricted by the IC-DE2 constraint, but also cannot exceed $\tilde{e}$, which itself is generally decreasing in $D$. In any case, effort close to $e^{F B}$ can only be implemented for rather low debt levels.

\section{Conclusion}

This paper has developed a relational contracting model to analyze financing behavior of firms from a new angle. An important feature of this model is that debt financing reduces the enforceability of implicit arrangements between a firm and its workforce. More equity is associated with more credibility and more commitment when a firm makes promises. One straightforward implication is that enterprises with well-functioning relational contracts should be less leveraged, on average. Another implication is that even profitable enterprises may use very little or no debt in order to maintain their credibility towards managers/workers.

Our analysis also sheds new light on empirical evidence suggesting that many firms exploit tax benefits associated with debt financing only to a limited extent or not at all. This empirical evidence is at odds with many agency cost/tradeoff models, where a firm's debt ratio has to be sufficiently large to actually trigger a bankruptcy and consequently cause costs of financial distress. Even if these costs are, on average, underestimated in empirical studies (see Molina, 2005), this does not explain why particularly healthy and profitable firms hardly use debt (Myers, 2003). Our model provides a rationale for this and shows that it can be optimal for a firm with low bankruptcy risk to exhibit low (or even zero) debt. In future work, we plan to explicitly analyze the interaction between tax benefits of debt and the enforceability of relational contracts, and how we expect different firms to react to tax incentives.

Our study indicates that empirical predictions obtained from theories suggesting target capital structures (e.g., Hovakimian, Hovakimian, Tehranian, 2004) may be misleading, as our model predicts a lower (endogenously determined) debt threshold or target debt ratio. Around this threshold, standard incentive considerations as in a tradeoff context might be dominated by considerations about the enforceability of relational contracts. The latter point could explain why some firms are responding in a discontinuous way (or not at all) to changes in institutional (policy) incentives such as taxes.

Finally, while we model a specific situation in which financial choices affect the sustainability of relational contracts, our mechanism is relevant in other situations where long-term relationships are important. For example, future research might explore the way how financing affects long-term relationships in the franchising business. ${ }^{29}$ Franchisors often require a minimum equity ratio from franchisees (Fraja and Piga, 2004). Applying the mechanisms derived in the paper to franchising relationships might lead to interesting insights and a better understanding of firm behavior, including financial choices made by firms operating under this specific organizational form.

\footnotetext{
${ }^{29}$ We believe that franchising is a particularly interesting example as this type of business model is often related to agency problems (see Lafontaine, 1992, for an overview).
} 


\section{Appendix I: Omitted proofs}

Proof of Lemma 3: Generally, the principal's dynamic enforcement (DE) constraint must hold in every period. There, she either might repay the loan after reneging on paying the bonus or not, depending on what kind of deviation delivers higher profits. In the first case, the (DE) constraint equals

$$
-\lambda(\theta) b-\lambda(\theta) r D+\delta \Pi(1) \geq-\lambda(\theta) r D+\delta \hat{\Pi}(0),
$$

with $\hat{\Pi}(0)=\lambda(\theta)\left[\alpha \frac{f(0)-\bar{u}}{1-\delta \rho}-\frac{\rho r D^{0}}{1-\delta \rho}\right]$.

In the second case, it becomes

$$
-\lambda(\theta) b-\lambda(\theta) r D+\delta \Pi(1) \geq 0
$$

Note that condition (4) also implies that repaying the loan is optimal after rewarding the agent (which requires $-\lambda(\theta) r D+\delta \Pi(1) \geq 0$ ).

We want to show that condition 3 is the relevant constraint. This holds of the right-handside of 3 is larger than the right-hand-side of (4), i.e., if $-\lambda(\theta) r D+\delta \hat{\Pi}(0) \geq 0$, where $\hat{\Pi}(0)=$ $\lambda(\theta)\left[\alpha \frac{f(0)-\bar{u}}{1-\delta \rho}-\frac{\rho r D}{1-\delta \rho}\right]$ and $r=\frac{1-\delta}{\delta}$. This condition becomes

$$
\delta \alpha \frac{f(0)-\bar{u}}{1-\delta \rho} \geq \frac{1-\delta}{\delta(1-\delta \rho)} D
$$

which holds for all $D \in[0, K-I]$ due to Assumption 2. Q.E.D.

Proof of Lemma 4: Using previous results, the (IC) constraint becomes $b-c+\delta(1-\alpha)\left[\frac{f(1)-c-\bar{u}}{1-\delta}-\rho \frac{f(0)-\bar{u}}{1-\delta \rho}\right] \geq$ 0 , the (DE) constraint becomes $-b+\delta \alpha\left[\frac{(f(1)-c-\bar{u})}{1-\delta}-\frac{f(0)-\bar{u}}{1-\delta \rho}\right]-D \frac{1-\rho}{1-\delta \rho} \geq 0$. Adding both gives the (IC-DE) constraint, proving necessity.

Concerning sufficiency, assume condition (IC-DE) holds. Set $b \equiv \max \left\{0, c-\delta(1-\alpha)\left[\frac{f(1)-c-\bar{u}}{1-\delta}-\rho \frac{f(0)-\bar{u}}{1-\delta \rho}\right]\right\}$, which satisfies the (IC) constraint by construction. For $b=c-\delta(1-\alpha)\left[\frac{f(1)-c-\bar{u}}{1-\delta}-\rho \frac{f(0)-\bar{u}}{1-\delta \rho}\right]$, plugging this into (IC-DE) yields $\delta \alpha\left(\frac{f(1)-c-\bar{u}}{1-\delta}-\frac{f(0)-\bar{u}}{1-\delta \rho}\right)-\frac{(1-\rho)}{(1-\delta \rho)} D \geq b$, which is equivalent to (DE). For $b=0$, the (DE) constraint becomes $\delta \alpha\left[\frac{(f(1)-c-\bar{u})}{1-\delta}-\frac{f(0)-\bar{u}}{1-\delta \rho}\right]-D \frac{1-\rho}{1-\delta \rho} \geq 0$, which does not automatically hold given (IC-DE). However, note that due to Assumption 2, we know that $\alpha \delta^{2} \rho \frac{f(0)-\bar{u}}{1-\delta \rho} \geq$ $(K-I)$. Since $f(1)-c-\bar{u}>f(0)-\bar{u}$ and $D \leq K-I$ for any relevant debt level, Assumption $2 \mathrm{im}-$ plies $\alpha \delta^{2} \rho \frac{f(1)-c-\bar{u}}{1-\delta \rho} \geq D$, and hence $\alpha \geq \frac{D}{\delta^{2} \rho \frac{f(1)-c-\bar{u}}{1-\delta \rho}}$. Therefore, $\delta \alpha\left[\frac{(f(1)-c-\bar{u})}{1-\delta}-\frac{f(0)-\bar{u}}{1-\delta \rho}\right]-D \frac{1-\rho}{1-\delta \rho} \geq$ $\delta \frac{D}{\delta^{2} \rho \frac{f(1)-c-\bar{u}}{1-\rho \delta}}\left[\frac{(f(1)-c-\bar{u})}{1-\delta}-\frac{f(0)-\bar{u}}{1-\delta \rho}\right]-D \frac{1-\rho}{1-\delta \rho}$ $=\frac{D}{\delta \rho(f(1)-c-\bar{u})}\left\{\frac{1-\delta \rho-\delta \rho(1-\delta)-\delta \rho(1-\rho)}{(1-\delta)(1-\delta \rho)}(f(1)-c-\bar{u})-(f(0)-\bar{u})\right\}$. Since $\frac{1-\delta \rho-\delta \rho(1-\delta)-\delta \rho(1-\rho)}{(1-\delta)(1-\delta \rho)} \geq 1$, this term is positive and the (DE) constraint satisfied for $b=0$. Q.E.D. 
Proof of Proposition 2: The objective of the principal is to maximize profits $\Pi_{0}$. Implementing $e=1$ is only feasible if constraint (IC-DE) is satisfied. Since the left-hand side of (IC-DE) is decreasing in $D$, and since $D \in[0, K-I]$, we have three possible cases:

1. The (IC-DE) constraint does not hold for $D=0$.

2. The (IC-DE) constraint holds for $D=K-I$.

3. The (IC-DE) constraint holds for $D=0$, but not for $D=K-I$.

For 1. and 2., the capital structure does not affect the enforceability of relational contracts. In 1. relational contracts are never feasible; in 2. relational contracts are always feasible. In these cases, the (IC-DE) constraint is irrelevant, and the situation is equivalent to benchmark I (case 1.) or benchmark II (case 2.). Then, the principal only takes into account the direct costs when determining its financing structure. As shown in Lemmas 1 and 2, this implies that $D^{*}=K-I$ and $E^{*}=0$.

Suppose we are in 3. This implies that there exists a debt level $\tilde{D} \in[0, K-I$ ), such that (IC-DE) (i) holds as an equality for $D=\tilde{D}$, (ii) is strictly satisfied for $D<\tilde{D}$, and (iii) does not hold for $D>\tilde{D}$. It remains to be shown that $D^{*}=\tilde{D}$.

Assume $D^{*}<\tilde{D}$, which implies that high effort can be enforced. Referring to the proof of Lemma 2 , profits of the principal are

$$
\Pi_{0}(1)=-K+l(\beta) \beta(\theta) D^{*}+(1-l(\beta) \beta(\theta)) \delta \alpha \frac{f(1)-c-\bar{u}}{1-\delta} .
$$

Increasing $D^{*}$ by a small $\varepsilon>0$ (weakly) increases $\Pi_{0}(1)$, without violating the (IC-DE) constraint. Hence, the principal prefers $D^{*}=\tilde{D}$ over $D^{*}<\tilde{D}$.

Assuming $D^{*}>\tilde{D}, e=1$ cannot be enforced. Referring to the proof of Lemma 2, profits of the principal are

$$
\Pi_{0}(0)=-K+l(\beta) \beta(\theta) D^{*}+(1-l(\beta) \beta(\theta)) \delta \alpha \frac{f(0)-\bar{u}}{1-\delta \rho} .
$$

Reducing $D^{*}$ to $\tilde{D}$ leads to profits $-K+l(\beta) \beta(\theta) \tilde{D}+(1-l(\beta) \beta(\theta)) \delta \alpha \frac{f(1)-c-\bar{u}}{1-\delta}$, and the change in profits amounts to

$$
\begin{aligned}
\Delta & \Pi_{0}=l(\beta) \beta(\theta)\left(\tilde{D}-D^{*}\right)+(1-l(\beta) \beta(\theta)) \delta \alpha\left(\frac{f(1)-c-\bar{u}}{1-\delta}-\frac{f(0)-\bar{u}}{1-\delta \rho}\right) . \text { Because } \tilde{D} \geq 0 \text { and } D^{*} \leq K-I, \\
& l(\beta) \beta(\theta)\left(\tilde{D}-D^{*}\right)+(1-l(\beta) \beta(\theta)) \delta \alpha\left(\frac{f(1)-c-\bar{u}}{1-\delta}-\frac{f(0)-\bar{u}}{1-\delta \rho}\right) \\
& \geq-l \beta(\theta)(K-I)+(1-l \beta(\theta)) \delta \alpha\left(\frac{f(1)-c-\bar{u}}{1-\delta}-\frac{f(0)-\bar{u}}{1-\delta \rho}\right) \\
& =l(\beta) \beta(\theta)\left(-(K-I)+\delta \alpha \frac{f(0)-\bar{u}}{1-\delta \rho}\right)+\delta \alpha\left((1-l(\beta) \beta(\theta)) \frac{f(1)-c-\bar{u}}{1-\delta}-\frac{f(0)-\bar{u}}{1-\delta \rho}\right), \text { where the first term }
\end{aligned}
$$

is positive because of Assumption 2, and the second term is positive because of Assumption 4. Hence, the principal prefers $D^{*}=\tilde{D}$ over $D^{*}>\tilde{D}$. Q.E.D. 


\section{Appendix II: Benchmark cases}

\section{Benchmark I: $e_{t}=0$ in all periods}

As a benchmark case, we develop a profit-maximizing equilibrium with $e_{t}=0$ in all periods, assuming that the firm has been started and the investment $K$ been made. For this to be interesting, $f(0)$ has to be strictly positive and sufficiently large. Naturally, this implies that $f(0) \geq \bar{u}$.

Recall that the principal also needs the agent to operate the firm if $e=0$. The reason is that $e=0$ does not imply that the agent is completely unproductive, only that he is not willing to exert extra, non-verifiable, effort. If the agent is employed by the firm, he receives a share $1-\alpha$ of the surplus generated by this relationship.

The relationship surplus amounts to $\frac{f(0)-\bar{u}}{1-\delta \rho}$. In every period the agent gets her outside option $\bar{U}$ plus the share $1-\alpha$ of the relationship surplus:

$$
U(0)=\bar{U}+(1-\alpha) \frac{f(0)-\bar{u}}{1-\delta \rho} .
$$

We denote the principal's profits in an equilibrium with $e=0$ by $\Pi(0)$. For a given share $1-\theta$ of external financing and a given debt level $D$, those are

$$
\Pi(0)=\lambda(\theta)\left[\alpha \frac{f(0)-\bar{u}}{1-\delta \rho}-\frac{\rho r D}{1-\delta \rho}\right]
$$

with $\lambda(\theta)=[1-l(\beta)] \beta(\theta)+(1-\beta(\theta)) \theta$.

Finally, a creditor's zero-profit condition, $-D+\delta \rho(1+r) D=0$, determines the interest rate $r$ and yields

$$
r=\frac{1-\delta \rho}{\delta \rho}
$$

Note that this holds for all periods $t \geq 2$. Concerning the debt issued in period $t=0$ and repaid in $t=1$, the interest rate actually amounts to $(1-\delta) / \delta$ because the first time the firm may face a bankruptcy shock is at the end of period 1.

Given $e=0$, a voluntary default is not optimal if

$$
-\lambda(\theta) r D+\delta \Pi(0) \geq 0
$$

This condition becomes

$$
-\frac{D}{\delta \rho}+\alpha \delta \frac{f(0)-\bar{u}}{1-\delta \rho} \geq 0
$$

So, when it comes to the question whether to default or not, the interests of the principal and providers of external capital are fully aligned.

Condition (5) also determines whether and to what extent the firm is credit constrained. Being credit constrained, the firm would like to borrow more but is not granted additional credit, even if it is willing to pay a higher interest rate. This is driven by debt making a voluntary default more 
tempting and by the fact that - given a voluntary default is optimal - the creditor is not willing to lend at all.

Lemma A1: Assume the firm has been started and $e_{t}=0$ in every period the firm is active. Then, the following conditions determine the firm's maximum equilibrium debt level $D^{\text {max }}$ :

- If $\alpha \delta \frac{f(0)-\bar{u}}{1-\delta \rho} \geq \frac{K-I}{\delta \rho}$, then $D^{\max }=K-I$.

- If $\alpha \delta \frac{f(0)-\bar{u}}{1-\delta \rho}<\frac{K-I}{\delta \rho}$, then $D^{\max }=\alpha \rho \delta^{2}\left(\frac{f(0)-\bar{u}}{1-\delta \rho}\right)$.

Proof: This follows from (6). The left-hand side is decreasing in D. Furthermore, the firm's need for external capital amounts to $K-I$, and it will (by assumption) never borrow more. Therefore, if (6) holds for $K-I$, the firm is not credit constrained and can borrow, and $D^{\max }=K-I$. Otherwise, (6) is violated for $K-I$, and, by setting it equal to zero and solving for $D$, yields $D^{\max }$. Q.E.D.

In a next step, we show that the firm's optimal debt level is actually given by $D^{\max }$.

Lemma A2: Assume the firm has been started and $e_{t}=0$ in every period the firm is active. Then, its optimal debt level is given by $D^{\max }$.

Proof: The value of the external equity amounts to $\Pi^{E}(0)=[1-\beta(\theta)](1-\theta)\left[\alpha \frac{f(0)-\bar{u}}{1-\delta \rho}-\frac{\rho r D}{1-\delta \rho}\right]$. Furthermore, $K-I=E+D$ and $E=\delta \Pi^{E}(0)$. Therefore, for a given debt level $D$, the principal's share $\theta$ is determined by $K-I-D=\delta \Pi^{E}(0)$, with $\frac{d \theta}{d D}=\frac{1-(1-\beta(\theta))(1-\theta)}{\delta\left[\beta^{\prime}(\theta)(1-\theta)+(1-\beta(\theta))\right] \frac{\alpha(f(0)-\bar{u})-\rho r D}{1-\delta \rho}}>0$. Using this, the principal's profits at the beginning of the game are

$$
\Pi_{0}(0)=-I+\delta \Pi(0)=-K+l(\beta) \beta(\theta) D+[1-l(\beta) \beta(\theta)] \delta \alpha \frac{f(0)-\bar{u}}{1-\delta \rho},
$$

with $\frac{d \Pi_{0}(0)}{d D}=l(\beta) \beta(\theta)-\left(l^{\prime} \beta(\theta)+l(\beta)\right) \beta^{\prime} \frac{d \theta}{d D}\left(\delta \alpha \frac{f(0)-\bar{u}}{1-\delta \rho}-D\right)>0$. Therefore, having $D^{\max }$ is strictly optimal. Q.E.D.

Together with Assumption 2, Lemma A2 also implies Lemma 1 in the main part.

Finally, note that the expression $\Pi_{0}(0)=-K+l(\beta) \beta(\theta) D+[1-l(\beta) \beta(\theta)] \delta \alpha \frac{f(0)-\bar{u}}{1-\delta \rho}$ also leads to Assumption 3. If it is positive for $D=0$ (for which it is minimized), starting the firm is optimal in any case.

\section{Benchmark II: Formal contracts feasible}

In this benchmark, we derive the optimal outcome if the agent's effort is verifiable. Consider the following agreement. The agent receives the fixed wage $w$. If $e=1$, he also gets a bonus $b \geq 0$, whereas no bonus is paid in case of $e=0$. 
The payments must give the agent a utility level of $U(1)=\frac{w+b-c}{1-\delta}=\bar{U}+(1-\alpha) \frac{f(1)-\bar{u}}{1-\delta}$, and further induce him to exert effort in every period. The latter aspect is captured by an incentive compatibility (IC) constraint, which equals

$$
-c+b+\delta U(1) \geq \delta(\rho U(1)+(1-\rho) \bar{U})
$$

It is straightforward to show that both objectives can be (non-uniquely) achieved by setting $w=\alpha \bar{u}+(1-\alpha)(f(1)-c)$ and $b=c$.

This allows us to prove

Lemma 2: Assume the agent's effort is verifiable. Then, the firm is started and $e=1$ implemented in every period. Furthermore, the firm only uses debt to finance its need for external capital, i.e., $D=K-I$.

Proof: The value of the external equity amounts to $\Pi^{E}(1)=[1-\beta(\theta)](1-\theta) \frac{\alpha(f(e)-c-\bar{u})-r D}{1-\delta}$, with $\frac{d \theta}{d D}=\frac{1-(1-\beta(\theta))(1-\theta)}{\delta\left[\beta^{\prime}(\theta)(1-\theta)+(1-\beta(\theta))\right] \frac{\alpha(f(e)-c-\bar{u})-r D}{1-\delta}}>0$. Using this, the principal's profits at the beginning of the game are

$$
\Pi_{0}(1)=-I+\delta \Pi(1)=-K+l(\beta) \beta(\theta) D+[1-l(\beta) \beta(\theta)] \frac{\delta \alpha(f(e)-c-\bar{u})}{1-\delta},
$$

with $\frac{d \Pi_{0}(1)}{d D}=l(\beta) \beta(\theta)-\left[l^{\prime} \beta(\theta)+l(\beta)\right] \beta^{\prime} \frac{d \theta}{d D}\left(\delta \alpha \frac{f(e)-c-\bar{u}}{1-\delta}-D\right)>0$. Therefore, having $D=K-I$ is strictly optimal.

Finally, starting the firm with $e=1$ is optimal in any case if $-K+[1-l(\beta) \beta(\theta)] \frac{\delta \alpha(f(e)-c-\bar{u})}{1-\delta} \geq 0$, which holds because of Assumption 3 and $f(1)-c>f(0)>\bar{u}$. Q.E.D. 


\section{References}

[1] Abreu, D. (1988), "On the theory of infinitely repeated games with discounting." Econometrica, $56,383-396$.

[2] Airlines.org, http://www.airlines.org/Pages/U.S.-Airline-Bankruptcies-and-ServiceCessations.aspx (Accessed: April 24, 2014).

[3] Bae, K.-H., Kang, J.-K., and J. Wang (2011), "Employee treatment and firm leverage: A test of the stakeholder theory of capital structure," Journal of Financial Economics, 100(1), 130-153.

[4] Bebchuk, L.A., and L.A. Stole (1993), "Do short-term objectives lead to under- or overinvestment in long-term projects," Journal of Finance, 48, 719-729.

[5] Benmelech, E., Bergman, N.K., and R.J. Enriquez (2012), "Negotiating with labor under financial distress," Review of Corporate Finance Studies, 1, 28-67.

[6] Berk, J., Stanton, R., and J. Zechner (2010), "Human capital, bankruptcy and capital structure," Journal of Finance, 65, 891-926.

[7] Bolton, P., and D. Scharfstein (1990), "A theory of predation based on agency problems in financial contracting," American Economic Review, 80, 93-106.

[8] Brander, J. and T. Lewis (1986), "Oligopoly and financial structure: The limited liability effect," American Economic Review, 76, 956-970.

[9] Bull, C. (1987), "The existence of self-enforcing implicit contracts," The Quarterly Journal of Economics, 102(1), 147-159.

[10] DeVaro, J., Kim, J.-H., and N. Vikander (2014), "Evidence for relational contracts in CEO bonus compensation," mimeo.

[11] Dewatripont, M., and J. Tirole (1994), "A theory of debt and equity: Diversity of securities and manager-shareholder congruence," Quarterly Journal of Economics, 69, 811-838.

[12] Ellingsen, T. and E.G. Kristiansen (2011), "Financial contracting under imperfect enforcement," The Quarterly Journal of Economics, 126, 323-371.

[13] Englmaier, F. and M. Fahn (2016), "Size Matters - 'Over'investments in a relational contracting model," mimeo.

[14] Fool.com, http://www.fool.com/investing/general/2012/11/02/five-reasons-why-southwestairlines-is-a-value-pla.aspx\#.UsaWrrSMmw8 (Accessed: February 20, 2014).

[15] Fahn, M., V. Merlo, and G. Wamser (2014), "The commitment role of equity financing," CESifo Working Paper No. 4841. 
[16] Fraja, G. and C. Piga (2004), "Strategic debt in vertical relationships: Theory and evidence", Research in Economics, 58, 103-123.

[17] Gibbons, R. (2010), "Inside organizations: Pricing, politics, and path dependence," Annual Review of Economics, 2, 337-365.

[18] Gibbons, R. and R. Henderson (2013), "What do managers do? Exploring persistent performance differences among seemingly similar enterprises," in R. Gibbons and John Robert (edts.), The Handbool of Organizational Economics, Princeton University Press, 680-731.

[19] Glassdoor.com, http://www.glassdoor.com/about/best-places-to-work.htm (Accessed: April 20, 2014).

[20] Graham, J.R. (1996), "Proxies for the corporate marginal tax rate," Journal of Financial Economics, 42, 187-221.

[21] Graham, J.R. (2000), "How big are the tax benefits of debt?" Journal of Finance, 55, 1901-1941.

[22] Graham, J.R. and M.T. Leary (2011), "A review of empirical capital structure research and directions for the future," Annual Review of Financial Economics, 3, 309-345.

[23] Graham, J.R. and D.A. Rogers (2002), "Do firms hedge in response to tax incentives?" The Journal of Finance, 57, 815-839.

[24] Harris, M. and A. Raviv (1991), "The theory of capital structure," Journal of Finance, 46, 297-355.

[25] Hart, Oliver D., and John Moore (1995), "Debt and seniority: An analysis of the role of hard claims in constraining management," American Economic Review, 113, 1-41.

[26] Hart, Oliver D., and John Moore (1998), "Default and renegotiation: A dynamic model of debt," Quarterly Journal of Economics, 63, 1-41.

[27] Hastings, D. (1999), "Lincoln Electric's harsh lessons from international expansion," Harvard Business Review, 77(3), 162-178.

[28] Heaton, J.B. (2002), "Managerial optimism and corporate finance," Financial Management, 31, $33-45$.

[29] Hennessy, C.A., and D. Livdan (2009), "Debt, bargaining, and credibility in firm-supplier relationships," Journal of Financial Economics, 93, 382-399.

[30] Holmstrom, B. and J. Tirole (1997), "Financial intermediation, loanable funds, and the real sector," Quarterly Journal of Economics, 62(3), 663-691. 
[31] Hovakimian, A., G. Hovakimian, and H. Tehranian (2004), "Determinants of target capital structures: The case of dual debt and equity issues," Journal of Financial Economics, 71, $517-540$.

[32] Inderst, R., and H. M. Müller (2003), "Internal versus external financing: An optimal contracting approach," The Journal of Finance, 58(1), 1033-1062.

[33] Jensen, M.C., and W.R. Meckling (1976), "Theory of the firm, managerial behaviour, agency costs and ownership structure," Journal of Financial Economics, 3, 305-360.

[34] Jensen, M.C. (1986), "Agency costs of free cash flows, corporate finance, and takeovers," American Economic Review, 76, 323-329.

[35] Johnson, S., La Porta, R., Lopez-de-Silvanes, F., and A. Shleifer (2000), "Tunneling," American Economic Review: Papers and Proceedings, 90(2), 22-27.

[36] Lafontaine, F. (1992), "Agency theory and franchising: Some empirical results", RAND Journal of Economics, 23(2), 263-283.

[37] Leary, M.T. and M.R. Roberts (2010), "The pecking order, debt capacity, and information asymmetry," Journal of Financial Economics, 95, 332-355.

[38] Levin, J. (2003), "Relational incentive contract," The American Economic Review, 93(3), 835857.

[39] MacLeod, W.B. and J. Malcomson (1989), "Implicit contracts, incentive compatibility, and involuntary unemployment," Econometrica, 57(2), 447-480.

[40] Maksimovic, V. and S. Titman (1991), "Financial policy and reputation for product quality," Review of Financial Studies, 4, 175-200.

[41] Malcomson, J. (2013), "Relational incentive contracts," in R. Gibbons and John Robert (edts.), The Handbool of Organizational Economics, Princeton University Press, 1014-1065.

[42] Matsa, D. (2010), "Capital structure as a strategic variable: Evidence from collective bargaining," Journal of Finance, 65, 1197-1232.

[43] Miller, D.A. and J. Watson (2013), "A theory of disagreement in repeated games with bargaining," Econometrica, 81, 2303-2350.

[44] Modigliani, F. and M. Miller (1958), "The cost of capital, corporation finance, and the theory of investment," American Economic Review, 48, 261-297.

[45] Modigliani, F. and M. Miller (1963), "Corporate income taxes and the cost of capital: A correction," American Economic Review, 53, 433-443. 
[46] Molina, C.A. (2005), "Are firms underleveraged? An examination of the effect of leverage on default probabilities," The Journal of Finance, 60(3), 1427-1459.

[47] Myers, S.C. (1977), "Determinants of corporate borrowing," Journal of Financial Economics, $5,147-175$.

[48] Myers, S.C. and N. Majluf (1984), "Corporate financing and investment decisions when firms have information that investors do not have," Journal of Financial Economics, 13, 187-221.

[49] Myers, S.C. (2003), "Financing of Corporations," Handbook of the Economics of Finance.

[50] Roll, R. (1986), "The hubris hypothesis of corporate takeovers," Journal of Business, 59, 97-216.

[51] Rubinstein, A. (1982), "Perfect equilibrium in a bargaining model," Econometrica, 50, 97-109.

[52] Shleifer, A., and R.W. Vishny (1997), "A survey of corporate governance," Journal of Finance, $52(2), 737-783$.

[53] Shleifer, A., and D. Wolfenzon (2002), "Investor protection and equity markets," Journal of Financial Economics, 66, 3-27.

[54] Stein, J.C. (1989), "Efficient capital markets, inefficient firms: A model of myopic corporate behavior," Quarterly Journal of Economics, 104, 655-669.

[55] Stiglitz, J.E. and A. Weiss (1981), "Credit rationing and markets with imperfect information," American Economic Review, 71, 393-411.

[56] Stiglitz, J.E. and A. Weiss (1983), "Incentive effects of terminations: Applications to the credit and labor markets," American Economic Review, 73, 912-927.

[57] Strebulaev, I.A. and B. Yang (2013), "The mystery of zero-leverage firms," Journal of Financial Economics, 109(1), 1-23.

[58] Titman, S. (1984), "The effect of capital structure on a firm's liquidation decision," Journal of Financial Economics, 13, 137-151.

[59] Williamson, O.E. (1964), "The economics of discretionary behavior: Managerial objectives in a theory of the firm", Prentice Hall, Englewood Cliffs, NJ.

[60] Zwiebel, J. (1996), "Dynamic capital structure under management entrenchment," American Economic Review, 86, 1197-1215. 